Canadian

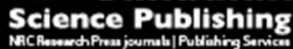

Canadian Geotechnical Journal Revue canadienne de géotechnique

Seismic assessment of the sheet pile reinforcement effect on river embankments constructed on a soft foundation ground including soft estuarine clay

\begin{tabular}{|r|l|}
\hline Journal: & Canadian Geotechnical Journal \\
\hline Manuscript ID & cgj-2016-0019.R3 \\
\hline Manuscript Type: & Article \\
\hline Date Submitted by the Author: & $21-$-Feb-2017 \\
\hline Keywlete List of Authors: & $\begin{array}{l}\text { Nakai, Kentaro; Nagoya University, Civil Engineering } \\
\text { Noda, Toshihiro; Nagoya University, Disaster Mitigation Research Center } \\
\text { Kato, Kenta; Nagoya University, Civil Engineering }\end{array}$ \\
\hline \multicolumn{2}{|c}{$\begin{array}{l}\text { Seismic response analysis, finite element method, river embankment, soft } \\
\text { clay, aseismic effect, steel pipe sheet pile }\end{array}$} \\
\hline \multicolumn{2}{|c}{} \\
\hline
\end{tabular}


Title: Seismic assessment of the sheet pile reinforcement effect on river embankments constructed on a soft foundation ground including soft estuarine clay

Authors: Kentaro Nakai $^{\mathrm{A})}$, Toshihiro Noda $^{\mathrm{B})}$ and Kenta Kato ${ }^{\mathrm{C})}$

\section{Affiliations and addresses}

A) Department of Civil Engineering, Nagoya University

Furo-cho, Chikusa, Nagoya, Aichi, 464-8603, JAPAN. nakai@civil.nagoya-u.ac.jp

B) Disaster Mitigation Research Center, Nagoya University

Furo-cho, Chikusa, Nagoya, Aichi, 464-8603, JAPAN. noda@civil.nagoya-u.ac.jp

C) Department of Civil Engineering, Nagoya University

Furo-cho, Chikusa, Nagoya, Aichi, 464-8603, JAPAN. katou.kenta@a.mbox.nagoya-u.ac.jp

Address correspondence to: Dr. Kentaro Nakai

Department of Civil Engineering, Nagoya University, Furo-cho, Chikusa, Nagoya, Aichi, 464-8603, JAPAN.

TEL: +81-52-789-5203, FAX: +81-52-789-3836, E-mail: nakai@civil.nagoya-u.ac.jp 


\begin{abstract}
Conventional seismic assessments of river embankments have focused on liquefaction damage of sandy ground.

However, following the 2011 earthquake centered off the Pacific Coast of Tohoku, extensive damage of river embankments built on clayey foundation has garnered greater attention. This paper presents seismic response analyses of river embankments constructed on soft and sensitive estuarine clay, as well as analyses of countermeasures implemented with sheet piles with a succession of penetration depth and place. River embankments kept stable if the clayey ground was assumed to be non-sensitive condition. However, if a strong shake impacts actual sensitive clay, there is a risk of slippage generated from the clayey layer. If the penetration depth of piles is shallow in the clayey layer, the clay is strongly disturbed by the tip of the pile, generating extensive damage; if the penetration depth is sufficiently deep in the supporting layer, significant deformation control may be obtained at the reinforced side, although there is a risk of promoting deformation at the opposite side. These results indicate the importance of the specific inspection of pile penetration depth, or else, not only sufficient countermeasure effect cannot be obtained but also adverse effect may be generated.
\end{abstract}

\title{
Keywords
}

Seismic response analysis, finite element method, river embankment, soft clay, aseismic effect, steel pipe sheet pile 


\section{Introduction}

In the 2011 earthquake centered off the Pacific Coast of Tohoku, more than 2000 river embankments were damaged in a wide area across the jurisdictions of the Tohoku and Kanto Regional Development Bureaus (Kazama and Noda 2012; Oka et al. 2012; Sasaki et al. 2012). The degree of damage ranged from minimal cracks to serious damage such as settlement, lateral flow, and slippage in the body of the river embankments. According to a survey taken after the earthquake disaster, the liquefaction of foundation ground and river embankment bodies was found to be the main cause of large-scale damage (Ministry 2012a). When liquefaction occurs, the height of a river embankment is lowered by lateral flow and consolidation settlement. Figure 1 summarizes the relationship between the initial height of a river embankment and the observed settlement caused by seismic motions since 1891 (Ministry 2012b), where the embankment height is an average value of the land and river sides, and the post-earthquake height was obtained from the maximum embankment height that satisfied the initial crown width.

Depending on the earthquake magnitude and duration, the ground condition, and other factors, the embankment settlement reaches up to $75 \%$ of the initial height, but does not surpass this limit.

Because floodplains in Japan are densely populated and contain many high-value properties, river embankments are important structures that protect people and property from floods and tidal waves. If a river embankment is damaged by an earthquake, there is a risk of significant inundation not only from the tsunami that often follows the earthquake, but also from rising water levels associated with tidal waves that may occur before the embankment is restored. Zero-meter zones, where the elevation is below Tokyo Bay's mean sea level, are spreading throughout extensive areas of Tokyo Bay, Ise Bay, and Osaka Bay on the Pacific coast. A future Nankai 
Trough mega earthquake is warily anticipated in these areas and this potential event carries a high risk of liquefaction. If river embankments are damaged such that these areas are inundated, the draining, rehabilitation, and reconstruction of these areas are expected to require a lengthy amount of time. However, the conventional seismic performance assessment and design focus only on the settlement caused by liquefaction of sandy foundation ground. Moreover, for simplicity, the seismic lateral force is often converted into an equivalent static lateral force (Ministry 2007). Therefore, conventional seismic design might underestimate and/or overlook seismic damage under other conditions. For instance, after the investigation of the 2011 earthquake centered off the Pacific Coast of Tohoku, the damage to river embankments constructed on clayey foundations has attracted more attention. Moreover, it has been discussed that, in addition to the liquefaction of the foundation soil, the settlement and deformation of the river embankment body caused by liquefaction should be considered to improve the accuracy of damage predictions. Nevertheless, the improved method remains insufficient because it only accounts for the liquefaction damage, and the deformation and destabilization of clayey soil by seismic motion are not considered. Seismic damage under these conditions is a serious concern because soft estuarine clay is thickly deposited near the estuaries of Tokyo Bay, Ise Bay, and Osaka Bay. However, in conventional seismic damage predictions, even in the case of soft clayey soil, or soil containing much sand and silt, soil that is classified as clayey soil is considered to preclude the possibility of seismic damage, and therefore clayey soil has always been modeled as an elastic material. That is, on soft ground where sensitive clayey soil is thickly deposited, conventional seismic damage predictions would not only underestimate the ground deformation but also overlook possible damage.

To date, the authors of this paper have been developing a soil-water coupled finite deformation analysis 
code (Noda et al. 2008a) that can represent the behavior of various soils — ranging from sand and intermediate soil to clay_within the same theoretical framework. This code can be applied to both ground deformation and failure and can be used to analyze coseismic behavior during an earthquake over a few seconds to a few minutes, as well as post-seismic behavior over a few years to a few centuries. The elasto-plastic equation of the soil skeleton mounted on this analysis code is the SYS Cam-clay model (Asaoka et al. 1998; Asaoka et al. 2000; and Asaoka et al. 2002), which describes the soil skeleton structure (structure, overconsolidation, and anisotropy) at work. With the SYS Cam-clay model as its base, this model is capable of describing disturbances occurring in loose sand and naturally deposited clay. Therefore, this analysis code can be used to investigate what will occur in the ground and how the damage will progress according to the types of external forces, such as embankment loads and seismic loads, to which the ground is subjected (Asaoka and Noda 2007; Noda et al. 2008a). This analysis code has been verified and validated by previous researches such as Noda et al. (2008b), Takaine et al. (2010) and Tani et al. (2015).

The research presented in this paper analyzed the seismic responses of river embankments in the Nobi Plain, where soft estuarine clay is thickly deposited under sandy soil with a high risk of liquefaction, and where the most extensive zero-meter zones in Japan cover approximately $274 \mathrm{~km}^{2}$. The target river embankment was constructed after the Tonankai earthquake in 1944, which was the latest large earthquake that has occurred in this area. Therefore, extensive seismic damage is anticipated in the area of this embankment because it has not experienced the motion of a large earthquake since the embankment's construction. This research focused not only on the sandy soil at the surface, but also on the seismic behavior of the clayey soil. Recently, the numerical analysis results 
showed that when clayey soil is very soft, in addition to the liquefaction of the subsurface sandy layer, a deep slip

failure occurs starting from the clayey layer, and the performance of river embankments is significantly degraded.

This paper also presents a numerical analysis of the aseismic effect of reinforcement using steel pipe sheet piles.

Because reinforcement with sheet piles is often performed as a measure against the liquefaction of the subsurface

sandy layer, the pile usually penetrates to the depth of the aquitard clayey layer. However, the comparative validation with the post-disaster investigations of the 2011 Tohoku Earthquake shows that if the tips of sheet piles are installed in the soft clayey layer, the clayey soil will be significantly disturbed by seismic motion, and the countermeasure may actually cause an adverse effect by increasing the damage to the river embankment.

\section{Analysis conditions}

\section{Finite element mesh and boundary conditions}

Figure 2 shows a geological cross-section near the estuaries of the rivers running through the Nobi Plain. According to the geological formation, ground consisting of alternate layers of sand and clay is formed, with a soft alluvial clayey layer thickly deposited beneath the subsurface alluvial sand layer. An in-situ boring survey revealed that a comparatively hard Pleistocene layer with a shear wave velocity of $V_{\mathrm{s}}>300 \mathrm{~m} / \mathrm{s}$ is deposited below a depth of $20 \mathrm{~m}$.

Figure 3 shows the finite element mesh and stratigraphic composition of the target ground before the construction of a river embankment. The analysis region was $1,000 \mathrm{~m}$ in width and $20 \mathrm{~m}$ in depth. The ground was assumed to be initially horizontally layered, with a 5-m Pleistocene layer (supporting layer) as the deepest layer, above which was a $10-\mathrm{m}$ sensitive soft alluvial clayey layer, followed by a $5-\mathrm{m}$ loose alluvial sandy layer. Figure 4 shows the 
construction history of the river embankment. Embankments $5 \mathrm{~m}$ in height with slope gradients of 1:1 were constructed on the initial ground by adding finite element meshes (Takaine et al. 2010). The crown of the right shore embankment was $7 \mathrm{~m}$, and that of the left shore one was $14 \mathrm{~m}$. After the embankment construction, a river channel was excavated by removing the finite element meshes (Takaine et al. 2010), and the river water level was made to rise up to Tokyo Peil T.P. $+1.2 \mathrm{~m}$.

By replicating the construction history as above, the effects of disturbance caused by the construction and excavation on the initial ground can be assessed. The hydraulic boundaries for the subsurface were designed as drained boundaries, and the bottom end and the two lateral faces were designed to be under undrained conditions.

Although the embankment body is usually in an unsaturated condition, the embankment was treated as saturated soil to represent the condition most relevant to the problem under investigation, such as after heavy rainfall or inundation by tidal waves. Accordingly, the hydraulic pressure was maintained to be always zero on the surface of the land side of the embankments and foundation ground. On the surface of the river side of the embankments, the hydraulic pressure was assigned according to the water level height. Periodic boundaries were realized by tying two nodes with the same height between both lateral ends (Asoaka et al. 1998; Noda et al. 2009).

\section{Determination of elasto-plastic properties for foundation soils and embankment}

The elasto-plastic properties (material constants and initial conditions) of the embankment, alluvial sand, and clay were all determined based on the results of mechanical tests using undisturbed samples obtained from boring surveys at the Tokai district river embankment shown in Figure 2. Table 1 shows the physical properties of the 
samples, and Figure 5 shows the grain size distribution curve for each layer. Following the engineering soil classification standards, the embankment material, alluvial sand, and alluvial clay were classified into sandy clay, fine fraction quality sand, and high liquid limit clay, respectively. Figures 6 and 7 show the results of undrained triaxial compression tests ( $\overline{\mathrm{CU}}$ tests) of the river embankment and alluvial sand, respectively. The specimens were sampled at the center of the embankment from the central part of each layer in the depth direction, and the confining pressures were $0.5 \sigma^{\prime}, 1.0 \sigma^{\prime}$, and $2.0 \sigma^{\prime}$, respectively, where $\sigma^{\prime}{ }_{v}$ is the overburden pressure.

Figure 8 shows the result of an undrained triaxial compression test (UU test) and a standard consolidation test of alluvial clay. Although the shear behaviors of the embankment material and alluvial sand showed strain hardening under any confining pressure, all $\mathrm{N}$-values measured in-situ were lower than 10 . Therefore, the risk of liquefaction is considered to be high (although a liquefaction strength test has not been performed). The mechanical behavior of alluvial clay shows a clear peak in shear behavior and bulky behavior in one-dimensional compression behavior which means the stress state is protrude outside the normally consolidated line, both of which are unique to sensitive clayey soil. Although the undrained shear strength was approximately $40 \mathrm{kPa}$, which seems sufficiently large, the shear strength drastically decreases after the failure. Moreover, the compression index $\lambda$ of the undisturbed sample was 0.500 while that of the remolded sample was 0.210 , indicating that this alluvial clay shows high compressibility in-situ.

In addition to these shear strength and compressibility characteristics, the $N$-value measured in-situ was nearly zero regardless of the depth (Figure 2), and the alluvial clay is therefore considered to be ultra-soft. The elasto-plastic properties were determined by replicating the results of these mechanical behaviors using the 
elasto-plastic constitutive model: namely, the SYS Cam-Clay Model (Asaoka et al. 2000; Asaoka et al. 2002), which describes the soil skeleton structure (structure, overconsolidation, and anisotropy) at work. For details on this model, see Appendix I. The SYS Cam-Clay model quantitatively defines the degree of bulk toward the normally consolidated line shown in Figure 8 as the structure. The larger denominator in $1 / R^{*}$ indicates a higher degree of structure, which represents the sensitive state. In contrast, as $1 / R^{*}$ approaches 1 , the degree of structure becomes reduced, which represents the remolded state. The numerical simulation results of the SYS Cam-Clay model are presented in Figures 6, 7, and 8, and Table 2 lists the identified elasto-plastic properties. Mechanical properties of undisturbed samples (stress-strain relationships and effective stress paths for embankment and alluvial sand, stressstrain relationships and compression behavior for alluvial clay) were well replicated by the numerical simulations.

The detailed explanations of each parameter are omitted here; however, to summarize, the initial degree of structure for alluvial clay was at a very high level, i.e., $1 / R^{*}=95$. The experimental results show that if the plastic deformation proceeds because of loading, the stress states gradually approach the normally consolidated line with ongoing structural decay, which is accompanied by large plastic compression. This compression behavior of clayey soil accompanied by soil disturbance (degradation of structure) is known to be the cause of secondary consolidation (Noda et al. 2005).

In the initial ground conditions, it was presumed that the degree of the soil skeleton structure and the stress ratio were uniform in each layer, and the specific volume was distributed in accordance with the overburden pressure. In the initial embankment conditions, considering that the embankment is constructed while being compacted, the specific volume of the embankment material was modeled as uniform within layers, and the 
overconsolidation ratio was distributed in accordance with the overburden pressure.

\section{Consolidation behavior during the embankment construction}

Figure 9 depicts the $1 / R^{*}$ structure distributions after the construction of the embankments. The alluvial clayey layer is initially in a highly structured state. As the construction process proceeds, the clayey soils directly beneath the embankments are disturbed, and the structure gradually degrades to some extent, nonetheless remaining in a highly structured state even after the end of consolidation. This behavior indicates that the structure does not easily degrade in response to static loading. Figure 10 depicts the amount of settlement that occurs at the crown of the embankment on the left shore: total settlement is approximately $0.55 \mathrm{~m}$, mostly in the alluvial clayey layer. Figure 11 shows a photo of the revetment at the corresponding location: there is a trace of revetment raising approximately $50 \mathrm{~cm}$ to $70 \mathrm{~cm}$ along the river. Although there are no accurate measurements, the settlement obtained from the analysis corresponds well with the settlement observed on-site.

\section{Seismic motion input}

The seismic motion input was a Tokai-Tonankai-Nankai triple-linked earthquake formulated by the Central Disaster Prevention Council (2004). This seismic motion is defined at the engineering bedrock with its shear wave velocity

$V_{s}=700 \mathrm{~m} / \mathrm{s}$. Therefore, the input value was amplified approximately twice in accordance with the $V_{\mathrm{s}}$ ratio between the engineering bedrock and the bottom end of the analytical region (Midorikawa 1987; Sugito et al. 2000). Figure 12 show the time history used in the analysis. Figure 13 shows the acceleration response spectrum with different 
damping factor $h$. A viscous boundary (Lysmer and Kuhlemeyer 1969; Noda et al. 2007) equivalent to $V_{\mathrm{s}}=300 \mathrm{~m} / \mathrm{s}$ was assumed in the horizontal direction on all nodes of the bottom face, and the seismic waveform was input in the horizontal direction equally on all nodes of the bottom face of the ground.

\section{Seismic behaviors of river embankments constructed on soft ground}

In Section 2, the Nobi Plain was described as containing sensitive and soft clayey soil that is deposited below the subsurface sandy soil. This section investigates how the condition of this clayey soil affects the seismic behavior of the river embankment. As shown in Table 3, seismic response analyses were conducted following two approaches:

Case $A$, where the actual sensitive condition of alluvial clayey soil was reproduced, and Case $B$, where a less structured condition was reproduced by decreasing the degree of the structure (the overconsolidation ratio is the same in both cases); accordingly, the specific volume in Case $A$ increased. Figure 14 shows the calculation results of the undrained shear and one-dimensional compression behaviors in each case. As mentioned above, Case $A$, in which clayey soil is sensitive (highly structured), shows a clear peak in shear behavior and bulky behavior during compression, but these characteristics are not observed in Case B, in which clayey soil is represented as non-sensitive (less structured).

Figures 15 and 16 depict the shear strain distributions in Case $A$ and Case B, respectively, over time. In both cases, shear strain in the alluvial sandy layer becomes large at the point of the principal motion of the earthquake, after a lapse of $30 \mathrm{~s}$ from the earthquake's onset. Figure 17 depicts the element behavior of sandy soil directly beneath the left shore embankment crown in Case $A$; although the figure is omitted, Case $B$ also shows 
similar behavior. Because stress ratio during earthquake was not so high and duration of seismic motion was long, decrease in the mean effective stress $p^{\prime}$ at the time of seismic motion approaches $p^{\prime}=0$, indicating liquefaction. The sandy layer loses its rigidity, subsequently resulting in settlement of the river embankment and lateral flow around the embankment toe, which can be identified in Figures 15 and 16. In the non-sensitive Case B, alluvial clayey soil shows a very small shear strain even at the end of the earthquake (Figure 16). On the other hand, in sensitive Case $A$, localized shear strain is generated at the point of primary motion in the upper region of the clayey layer. After a lapse of $60 \mathrm{~s}$ from the earthquake onset, slippage progresses towards both the river and land sides, and eventually proceeds to the ground surface, causing uplift of the riverbed. Along with slippage, significant settlement occurs even in the clayey layers immediately below the embankments.

Figure 18 shows the element behavior of clayey soil directly beneath the left shore embankment crown in Case $A$ and Case B. The fall in $p$ ' and decrease in rigidity are observed in clay as well, although not to the extent of that observed in sand. The comparison between Case A and Case B reveals that both the decrease in effective stress and the progression of strain are greater in Case A. This is because the sensitive clayey soil is strongly disturbed by seismic motion, and the structure is extensively degraded (Figure $18(\mathrm{c})$ ), which promotes the fall in $p^{\prime}$. In addition to the damage caused by settlement and lateral flow due to liquefaction of the sandy layer and disturbance of the clayey layer, the function of the river embankment is seriously impaired by the decrease in cross-section caused by the uplift of the river bed owing to slippage that begins from the clayey layer. Figure 19 shows the element behaviors of clayey soil that is distant from the river embankments. No significant difference is observed between Case $A$ and Case B, unlike the soil behavior directly beneath the river embankment. Moreover, the decrease in 
effective stress and progression of strain are not observed. This is because in the case of horizontal ground, a large shearing force does not work during an earthquake and the ground is not significantly disturbed, such that its structure is not significantly degraded.

Figures 20 and 21 depict the amount of settlement that occurs at the crown of the embankment on the left shore during the earthquake and the amount of horizontal displacement at the embankment toe, respectively; the right shore is not shown because no significant difference is observed between the right and left shore embankments. $80 \%$ of the total settlement is generated by the shear action of the earthquake, and $20 \%$ of the settlement is observed after the end of earthquake as a result of consolidation (dissipation of accumulated excess pore water pressure during an earthquake). Settlement in the embankment and the alluvial sand layer, in which permeability is large, converges as soon as the earthquake motion ended. On the other hand, the settlement in the alluvial clay layer, in which permeability is small, continues for more than 10 years. In contrast to these settlement characteristics, lateral displacement converged immediately after the end of the earthquake. The settlement is approximately $2.5 \mathrm{~m}$ during the earthquake and eventually approximately $3 \mathrm{~m}$ in Case $A$, whereas in Case $B$ the settlement is approximately $2.2 \mathrm{~m}$ during the earthquake and eventually approximately $2.4 \mathrm{~m}$. These differences are quite clear in the alluvial clayey soil because the sensitive clayey soil is strongly disturbed by the seismic motion. On the other hand, horizontal displacement is smaller in Case $A$. This is because the acceleration propagated in the direction of the embankment layer is attenuated by the decreased rigidity of the alluvial clayey layer owing to the strong disturbance.

From these analytical results, the river embankment does not show extensive deformation if the clayey 
ground is assumed to be in a less structured condition. On the other hand, if a strong shake occurs in highly structured clayey ground, the ground is significantly disturbed in the areas receiving eccentric loads, such as those directly beneath the river embankments. Moreover, sliding failure and a large settlement could also occur. In Case $A$, where actual river embankment conditions are assumed, a large settlement of almost $50 \%(2.50 \mathrm{~m})$ of the initial height occurs during an earthquake. Furthermore, the settlement reaches approximately $60 \%(3.00 \mathrm{~m})$ after the end of consolidation, which might lead to considerable degradation of the embankment performance. The embankment settlement obtained from the analysis might seem to be relatively large. However, the actual survey shown in Figure 1 indicates that depending on the earthquake magnitude, earthquake duration, and ground condition among other factors, the embankment settlement reaches up to $75 \%$ of the initial height. Therefore, the analysis result is not considered to be incompatible with the actual observations..

\section{Analytical assessment of reinforcement effect on the river embankment}

\section{Aseismic effect of steel pipe sheet pile method}

As a countermeasure against earthquakes, reinforcement by steel pipe sheet pile (hereafter, SPSP (Isobe et al.

2014)) is often used to inhibit the lateral flow caused by liquefaction. In general, the tips of sheet piles penetrate into the depth of the non-liquefiable layer. However, if the tip is fixed to the soft clayey layer, the seismic motion might cause the sheet piles to disturb the soft soil and the desired reinforcement effects will not be realized (Noda et al. 2009). In this section, as shown in Figure 22 and Table 4, to assess the reinforcement effects of the sheet piles, a series of seismic response analyses was conducted by changing the location and penetration depth of the sheet piles. 
The target ground was the same as that in Case $A$ in Section 3, in which clayey soil was in a highly structured condition. Therefore, in addition to the liquefaction of subsurface sandy soil, slippage failure of the soft clayey layer is also a concern. The SPSP was modeled as a one-phase linear elastic material. The sheet piles (700 mm in diameter and $10 \mathrm{~mm}$ in thickness) were assumed to be continuously connected perpendicular to the page; however, the analysis was conducted under two-dimensional plane strain conditions. Therefore, the density, Young's modulus, and yield stress were revised so that the weight, flexural rigidity, and yield moment became equivalent to the actual values, as shown in Table 5. The acting bending moment of the sheet pile was calculated from the stress condition at all times. If the bending moment exceeded the yield value, the sheet piles were considered to be too hard to resist further ground deformation. Therefore, through a step by step check and once moment exceeded yield value, the Young's modulus of the element was manually reduced to $1 / 100$ of its previous value in a simplified manner based on the fact that the constitutive equation of the iron member is frequently modeled by a bi-linear or tri-linear relationship with its stiffness degradation ranging from approximately $1 / 100$ to $1 / 1000$.

Aseismic effect of one-sided reinforcement on the river side

Figures 23, 24, 25, and 26 illustrate the shear strain distribution immediately after the principal motion of an earthquake, the structure distribution at the same moment, the amount of settlement at the crown of the left shore embankment, and the amount of horizontal displacement at the left shore embankment toe, respectively. When the penetration depth of the sheet pile was shallow, reaching only the clayey layer (Case $\left.A_{-} 1\right)$, the clayey soil was strongly disturbed and its structure was significantly degraded by the tip of the pile, and the clayey soil could not 
inhibit the lateral flow that enhanced the amount of uplift at the river bed. This is because slippage from the clayey layer occurs in a deeper region of the ground. Figure 27 shows the maximum value of the bending moment that acts on each node of the sheet pile member. Because the bending moments are very small, it is understandable that the sheet pile offers no resistance to the large deformation of the ground. In Case A_l, whole sheet piles were extruded to the river side by the lateral flow, finally causing a large uplift of the riverbed. On the other hand, when the sheet pile penetrated deep enough into the Pleistocene layer (Case A_2), even though the bending moment had almost reached the yield value at the boundary between the Pleistocene and clay layer, the pile was very effective at controlling deformation at the river side. Moreover, the disturbance of the clayey soil, and degradation of its structure, around the sheet pile was not obvious compared with Case A_l, where the tip of the pile was embedded into the clayey layer. However, this pile placement was found to promote horizontal displacement and uplift at the land side, which is inhabited by people, i.e., the reinforcement had the opposite effect in that area. Comparing the effects of placing sheet piles on the river side of the embankments, it can be seen that there are almost no significant reinforcement effects on the amount of settlement or the amount of stretching of the embankment body.

It has been reported that during the 2011 earthquake centered off the Pacific Coast of Tohoku, some of the severed sheet piles that had been installed since the construction of the embankments contributed to seismic resistance, although they were not intended as an earthquake countermeasure. On the other hand, an investigation of the damaged river embankments in the Kanto region (Committee 2013), as shown in Figure 28, found that although the severed sheet piles installed on the river side as an anti-inundation measure were effective at reducing the horizontal displacement on the river side (the side where the sheet piles were installed), they were not very 
effective at preventing the stretching at the embankment toe. On the contrary, the embankment moved to the land side, and the damage extended to nearby houses. The latter case is similar to the analytical results of this research, and it is therefore considered that soft foundation ground requires special attention.

Aseismic effect of reinforcements on the river and land sides

Let us consider Case $A \_3$ through Case $A \_6$, in which SPSPs were installed on both the river and land sides.

Figures 29, 30, 31, 32, and 33 illustrate the shear strain distribution immediately after the principal motion of an earthquake, the structure distribution at the same moment, the amount of settlement at the crown of the left shore embankment, the amount of horizontal displacement at the left shore embankment toe, and the maximum value of bending moment that acts on each node of the sheet pile member, respectively. Even though the bending moment exceeded the yield value, the ground deformation was strongly restricted when the penetration depth of the sheet pile was sufficiently deep into the Pleistocene layer on both the river and land sides (Case A_6). Therefore, significant reductions in the amounts of settlement and stretching of the embankment body were obtained, and the shear strain became smaller, especially in the clayey layer. This is because the shear deformation was strongly inhibited by the sheet piles, and therefore the disturbance of the clayey soil and degradation of its structure were prevented. When the penetration depth was shallow in some area, as in Case $A_{-} 3$ through Case $A_{-} 5$, even if the sheet piles were installed on both the river and land sides, the upper ends of the sheet piles spread in a V-shape, and large shear strains and horizontal displacements were generated at the side where the embedment was shallow. If the tip of the embedment was in the clayey layer, the clayey soil was significantly disturbed around the tip. 
Moreover, the bending moment acting on the sheet piles was as small as that in Case $A_{-} 1$, and the reinforcing effect of the sheet piles could not be realized. This phenomenon is a precise illustration of the saying, "Earthquakes cause damage by searching for the weakest link."

\section{Reinforcement effect on tie rod-type sheet pile cofferdam method}

The analytical results in the previous section showed that the reinforcement by SPSPs alone is not sufficient without deep embedment into the Pleistocene layer, because a sufficient reduction in the amount of settlement of the embankment and the amount of stretching of the embankment toe cannot be obtained. However, from both practical and economical viewpoints, it is difficult to embed the piles deep enough into the Pleistocene layer at all times. Therefore, this section discusses Case A_7, where seismic resistance was provided by the tie rod-type sheet pile cofferdam method (Japan 2001), in which the upper parts of the sheet piles are connected with tie rods to deter stretching. It was assumed that the penetration depth of the sheet pile was as shallow as that in Case $A_{-} 3$, and the tie rod was simply replicated by the constraint condition that the distances between two finite element nodes at the ends of the sheet piles were invariable (Asaoka et al. 1998; Noda et al. 2008b), as shown in Figure 34. Figure 35 shows the shear strain and structure distributions immediately after the principal motion of the earthquake.

Compared with having no countermeasure and with reinforcement with only sheet piles (Figures 23, 24, 29, and 30), this method was found to control the lateral flow of the foundation ground and reduce the amount of settlement. At the same time, the tie rod-type sheet pile played a significant role in reducing the stretching of the embankment toe. The maximum value of the bending moment that acts on each node of the sheet pile member is 
shown in Figure 36. Because of the tie-rods, the bending moment acting on the piles is slightly small even though the lateral flow of the embankment was restricted. The change in the axial force on the tie rod with the passage of time is shown in Figure 37. The tensile action of the axial force was regarded as positive. When an earthquake showed maximum acceleration, the axial force of the tie rod also reached its maximum value (approximately 700 $\mathrm{kN}$ ), indicating a correlation between the changes in acceleration and axial force. As time passed, the axial force of the tie rod stopped increasing and was reduced to approximately $150 \mathrm{kN}$ in consolidation after the earthquake. In this analysis, because the tie rod was replicated under a constraint condition, the response was considered to be that of a rigid material; therefore it can be assumed that the calculated force was greater than that applied to the actual cable. However, an axial force of $700 \mathrm{kN}$ can be borne by a tie rod with a larger diameter. As described above, if the SPSPs are connected with tie rods, the lateral displacement is significantly inhibited, which was revealed to effectively maintain the river embankment function. However, it is difficult to install tie rods on an existing embankment without excavating and backfilling the subsurface soils, and therefore this method might be most relevant to new or reconstructed embankments. Moreover, as the lower ends of SPSPs were not particularly restrained, the shear strain and disturbance in the lower part of the clay layer became large, and the formation of slip lines toward the surface layer was observed. In this case, the slip lines did not reach the ground surface; nonetheless, it is considered necessary to pay special attention to the penetration depth of the sheet piles.

\section{Conclusions}

This paper presented seismic response analyses of river embankments constructed on soft ground where soft clayey 
soil is deposited beneath the liquefiable sandy layer. In addition, the aseismic resistance effect of steel pipe sheet piles was numerically discussed through comparison with the post-disaster investigation results of the 2011 earthquake centered off the Pacific Coast of Tohoku. The main conclusions obtained from this analysis are as follows.

- River embankments did not show extensive deformation if the clayey ground was assumed to have a less structured condition. However, it has been pointed out that, if a strong shakes impacts highly structured clayey ground, i.e., in the areas receiving eccentric load like those directly under embankments, the ground is greatly disturbed and there is a risk of large settlement and slippage generated from the clayey layer.

- In the case of the installation of SPSPs at only the river side, if the penetration depth is shallow (Case A_2), the clayey soil is strongly disturbed by the tips of the sheet piles; as a result, a large shear strain occurs in the deep part of the clayey layer, and the lateral flow toward the river side cannot be inhibited. If the sheet pile is embedded into to the deep part of the Pleistocene layer, significant deformation control may be obtained at the river side. However, there is a risk of promoting horizontal displacements and uplifts at the land side, where there are dwellings, and therefore insufficient reinforcement may cause adverse effects.

- If the sheet piles are installed at both the river and land sides, when both piles penetrate sufficiently deep into the Pleistocene layer, a large reinforcement effect can be obtained. However, if either pile is shallow, a large shear strain and horizontal displacement occur at the shallower side, and as a result, the reinforcement effect cannot be obtained.

- A high constraint effect can be obtained by sheet piles that are connected with tie rods, even if the depth of the 
embedment of the SPSPs is shallow; this method was found to effectively reduce settlement and lateral displacement. However, the method still does not avoid disturbing the clayey soil.

Before 1995, seismic assessment in Japan was focused on level-1 seismic motion: medium-sized earthquakes that could possibly occur more than once during an in-service period. However, since the Great Hanshin-Awaji Earthquake of 1995, seismic assessments and countermeasures have been earnestly investigated, and since 2007, it has become mandatory to inspect level-2 seismic motion; that is, the largest scale of earthquakes within the range that can be presumed. However, for practical reasons, it is difficult to completely eliminate the deformation caused by the enormous seismic external force. Therefore, the aseismic resistance of a river embankment is defined as the ability of the river embankment to maintain its function against the outside water level even when deformation of the embankment (lateral flow, settlement, etc.) occurs. In the strata off the Pacific shore, which has a high risk of a Nankai Trough mega earthquake, ultra-soft clayey soil is often heavily deposited beneath the subsurface sandy layer. In this region where ultra-soft clayey soil is heavily deposited, seismic damage might be beyond the scope of prediction by the conventional method. Therefore, to avoid unintended damage, we should focus not only on the liquefaction damage of sandy soil on the surface but also on the instability of soft clayey soil, which has not been fully considered in conventional seismic performance assessment.

\section{Acknowledgements}

This research was supported in part by Grants-in-Aid from the Japan Society for the Promotion of Science (JSPS “Kakenhi” 20126012 and 25249064). Also, this paper reports on research carried out by the Technical 
Committee for the Mechanisms of Earthquake-Induced Ground Deformations (Chairman Akira Asaoka), a committee for seismic response research operating under the Japanese Geotechnical Society. 


\section{References}

Asaoka, A., and Noda, T. 2007. All soils all states all round geo-analysis integration. In Proceedings of the International Workshop on Constitutive Modelling-Development, Implementation, Evaluation, and Application, Hong Kong, China, 12-13 January 2007. Hong Kong Polytechnic University, Hong Kong, China, pp. 11-27.

Asaoka, A., Noda T., and Kaneda, K. 1998. Displacement/traction boundary conditions represented by constraint conditions on velocity field of soil. Soils and Foundations, 38(7): 173-181.

Asaoka A., Nakano M., and Noda, T. 2000. Superloading yield surface concept for highly structured soil behavior. Soils and Foundations, 40(2): 99-110.

Asaoka, A., Noda, T., Yamada, E., Kaneda, K., and Nakano, M. 2002. An elasto-plastic description of two distinct volume change mechanisms of soils. Soils and Foundations, 42(5): 47-57.

Central Disaster Prevention Council. 2004. Disaster Management, Reports and Brochures [online]. Availabe from www.bousai.go.jp/kaigirep/chuobou/senmon/tounankai_nankaijishin/datakoukai/index.html [accessed 10 February 2017.] (in Japanese)

Committee of Geotechnical Engineering, Japan Society of Civil Engineers. 2013. In Proceedings of the First Symposium on Embankment Technology from the Viewpoint of Geotechnical Engineering. Japan Society of Civil Engineers, Tokyo, Japan, 27-35 (in Japanese).

Hashiguchi, K. 1978. Plastic constitutive equations of granular materials. In Proceedings of the US-Japan Seminar on Continuum Mechanical and Statistical Approaches in the Mechanics of Granular Materials, Sendai, Japan, 
5-9 June 1978. Eds. Cowin, S.C., National Science Foundation, and Satake, M., Japan Society for the Promotion of Science, Tokyo, Japan, pp. 321-329.

Hashiguchi, K. 1989. Subloading surface model in unconventional plasticity. International Journal of Solids and Structures, 25: 917-945.

Isobe, K., Kimura, M., and Ohtsuka, S. 2014. Design approach to a method for reinforcing existing caisson foundations using steel pipe sheet piles. Soils and Foundations, 54(2): 141-154.

Japan Institute of Construction Engineering. 2001. Design manual for sheet pile temporary cofferdam method. Japan Institute of Construction Engineering, Minato, Japan (in Japanese).

Kazama, M., and Noda, T. 2012. Damage statistics: summary of the 2011 off the Pacific Coast of Tohoku Earthquake damage. Soils and Foundations, 52(5): 780-792.

Lysmer, J., and Kuhlemeyer, R.L. 1969. Finite dynamic model for inifinite media. Journal of the Engineering Mechanics Division, 98(EM4): 859-877.

Midorikawa, S. 1987. Prediction of isoseismal map in the Kanto plain due to hypothetical earthquake. Journal of Structural Engineering, 33(B): 43-48 (in Japanese).

Ministry of Land, Infrastructure, Transport, and Tourism. 2007. Guideline and exposition for inspection of seismic resistance of river structure II: river levee. Ministry of Land, Infrastructure, Transport, and Tourism, Tokyo, Japan (in Japanese).

Ministry of Land, Infrastructure, Transport, and Tourism. 2012a. Guideline and exposition for inspection of seismic resistance of river structure I: general. Ministry of Land, Infrastructure, Transport, and Tourism, Tokyo, Japan 
(in Japanese).

Ministry of Land, Infrastructure, Transport, and Tourism. 2012b. Guideline for inspection of seismic resistance of river structure against Level-2 earthquake. Ministry of Land, Infrastructure, Transport, and Tourism, Tokyo, Japan (in Japanese).

Noda, T., Asaoka, A., Nakano, M., Yamada, E., and Tashiro, M. 2005. Progressive consolidation settlement of naturally deposited clayey soil under embankment loading. Soils and Foundations, 45(5): 39-51.

Noda, T., Asaoka, A., and Nakano, M. 2008a. Soil-water coupled finite deformation analysis based on a rate-type equation of motion incorporating the SYS Cam-clay model. Soils and Foundations, 48(6): 771-790.

Noda, T., Nakai, K. and Asaoka, A. 2008b. Delayed failure of a clay foundation-embankment system after the occurrence of an earthquake. Theoretical and Applied Mechanics Japan, 57: 41-47.

Noda, T., Takeuchi, H., Nakai, K., and Asaoka, A. 2009. Co-seismic and post-seismic behavior of an alternately layered sand-clay ground and embankment system accompanied by soil disturbance. Soils and Foundations, 49(5): 739-756.

Oka, F., Tsai, P., Kimoto, S., and Kato, R. 2012. Damage patterns of river embankments due to the 2011 off the Pacific Coast of Tohoku Earthquake and a numerical modeling of the deformation of river embankments with a clayey subsoil layer. Soils and Foundations, 52(5): 890-909.

Sasaki, Y., Towhata, I., Miyamamto, K., Shirato, M., Narita, A., Sasaki, T., and Saka, S. 2012. Reconnaissance report on damage in and around river levees caused by the 2011 off the Pacific Coast of Tohoku Earthquake. Soils and Foundations, 52(5): 1016-1032. 
Sugito, M., Furumoto, Y., and Sugiyama, T. 2000. Strong motion prediction on rock surface by superposed evolutionary spectra. In Proceedings of the Twelfth World Conference on Earthquake Engineering, Auckland, New Zealand, 30 January-4 February 2000. New Zealand Society for Earthquake Engineering, Wellington, New Zealand, Paper No. 2111 (CD-ROM).

Takaine, T., Tashiro, M., Shiina, T., Noda, T., and Asaoka, A. 2010. Predictive simulation of deformation and failure of peat-calcareous soil layered ground due to multistage test embankment loading. Soils and Foundations, 50(2): 245-260.

Tani, K., Kiyota, T., Matsushita, K., Hashimoto, K., Yamamoto, A., Takeuchi, H., Noda, T., Kiku, H., and Obayashi, J. 2015. Liquefaction countermeasures by shallow ground improvement for houses and their cost analysis. Soil Dynamics and Earthquake Engineering, 79(B): 401-414. 


\section{Figure captions}

Figure 1 Observed settlement of the river embankment caused by earthquakes since 1891 (original drawings in Japanese are translated into English)

Figure 2 Geological cross-section near the estuaries of the rivers running through Nagoya City

Figure 3 Finite element mesh and stratigraphic composition of the target ground before the construction of the river embankment

Figure 4 Replication of the construction history of the river embankment by addition and removal of finite element meshes

Figure 5 Grain size distribution curves for each layer

Figure 6 Experimental and calculated results for undrained shear behavior of the river embankment material

Figure 7 Experimental and calculated results for undrained shear behavior of alluvial sand

Figure 8 Experimental and calculated results for undrained shear and one-dimensional compression behavior of alluvial clay

Figure 9 Structure distributions with the passage of time after the construction of the river embankment

Figure 10 Amounts of settlement at the crown of the left shore embankment after the construction of the river embankment

Figure 11 Trace of revetment raising

Figure 12 Seismic wave input used in the analysis

Figure 13 Acceleration response spectrum of the seismic motion input 
Figure 14 Calculated results for the undrained shear and one-dimensional compression behaviors with different initial structure conditions

Figure 15 Shear strain distributions with the passage of time for Case $A$

Figure 16 Shear strain distributions with the passage of time for Case B

Figure 17 Behavior of sand element directly beneath the left shore embankment crown for Case A

Figure 18 Behavior of clay element directly beneath the left shore embankment crown (comparison between Cases $A$ and $B$ )

Figure 19 Behavior of clay element distant from the river embankment (comparison between Cases $A$ and $B$ )

Figure 20 Amounts of settlement at the crown of the left shore embankment

Figure 21 Horizontal displacement at the toe of the left shore embankment

Figure 22 Location and penetration depth of the steel pipe sheet piles

Figure 23 Shear strain distributions immediately after the principal motion of an earthquake when the reinforcement is implemented on only the river side

Figure 24 Structure distributions immediately after the principal motion of an earthquake when the reinforcement is implemented on only the river side

Figure 25 Amounts of settlement at the crown of the left shore embankment when the reinforcement is implemented on only the river side

Figure 26 Amounts of horizontal displacement at the left shore embankment toe when the reinforcement is implemented on only the river side 
Figure 27 Maximum bending moment that acts on each node of the sheet pile member for Case A_1 and Case A_2

Figure 28 Results of actual damage investigation of river embankments in the Kanto region during the Tohoku Region Pacific Coast Earthquake (original drawings in Japanese are translated into English)

Figure 29 Shear strain distributions immediately after the principal motion of an earthquake when the reinforcement is implemented on both river and land sides

Figure 30 Structure distributions immediately after the principal motion of an earthquake when the reinforcement is implemented on both river and land sides

Figure 31 Amounts of settlement at the crown of the left shore embankment when the reinforcement is implemented on both river and land sides

Figure 32 Amounts of horizontal displacement at the left shore embankment toe when the reinforcement is implemented on both river and land sides

Figure 33 Maximum bending moment that acts on each node of the sheet pile member for Case $A \_3$ through Case A_6

Figure 34 Modeling of the tie rod-type sheet pile cofferdam method

Figure 35 Shear strain and structure distributions immediately after the principal motion of an earthquake with the tie rod-type sheet pile cofferdam method

Figure 36 Maximum bending moment that acts on each node of the sheet pile member for Case $A_{-} 7$

Figure 37 Changes in the axial force of the tie rod with the passage of time 

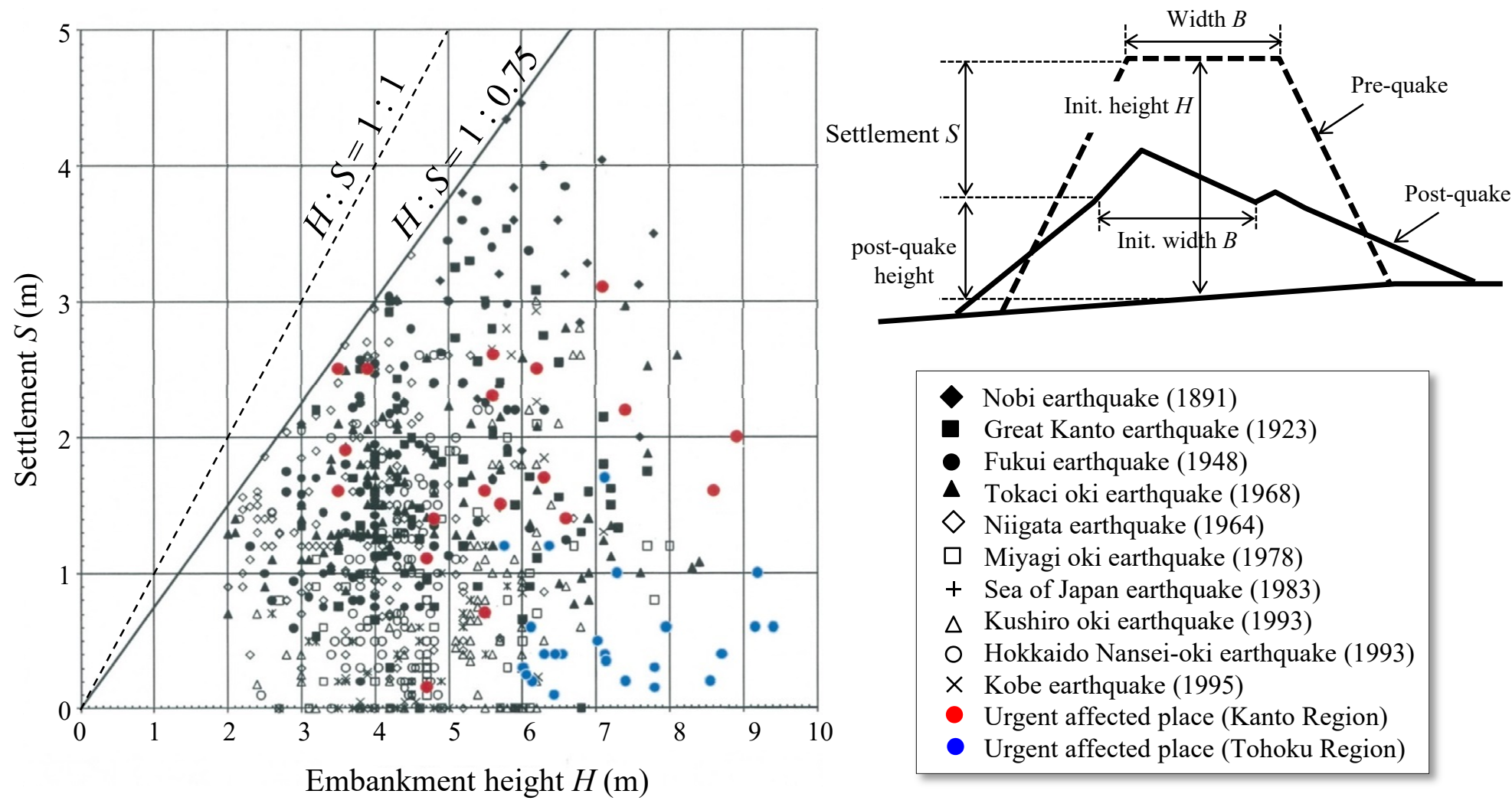

Nobi earthquake (1891)

- Great Kanto earthquake (1923)

- Fukui earthquake (1948)

- Tokaci oki earthquake (1968)

$\diamond$ Niigata earthquake (1964)

$\square$ Miyagi oki earthquake (1978)

+ Sea of Japan earthquake (1983)

$\Delta$ Kushiro oki earthquake (1993)

O Hokkaido Nansei-oki earthquake (1993)

$\times$ Kobe earthquake (1995)

- Urgent affected place (Kanto Region)

- Urgent affected place (Tohoku Region) 


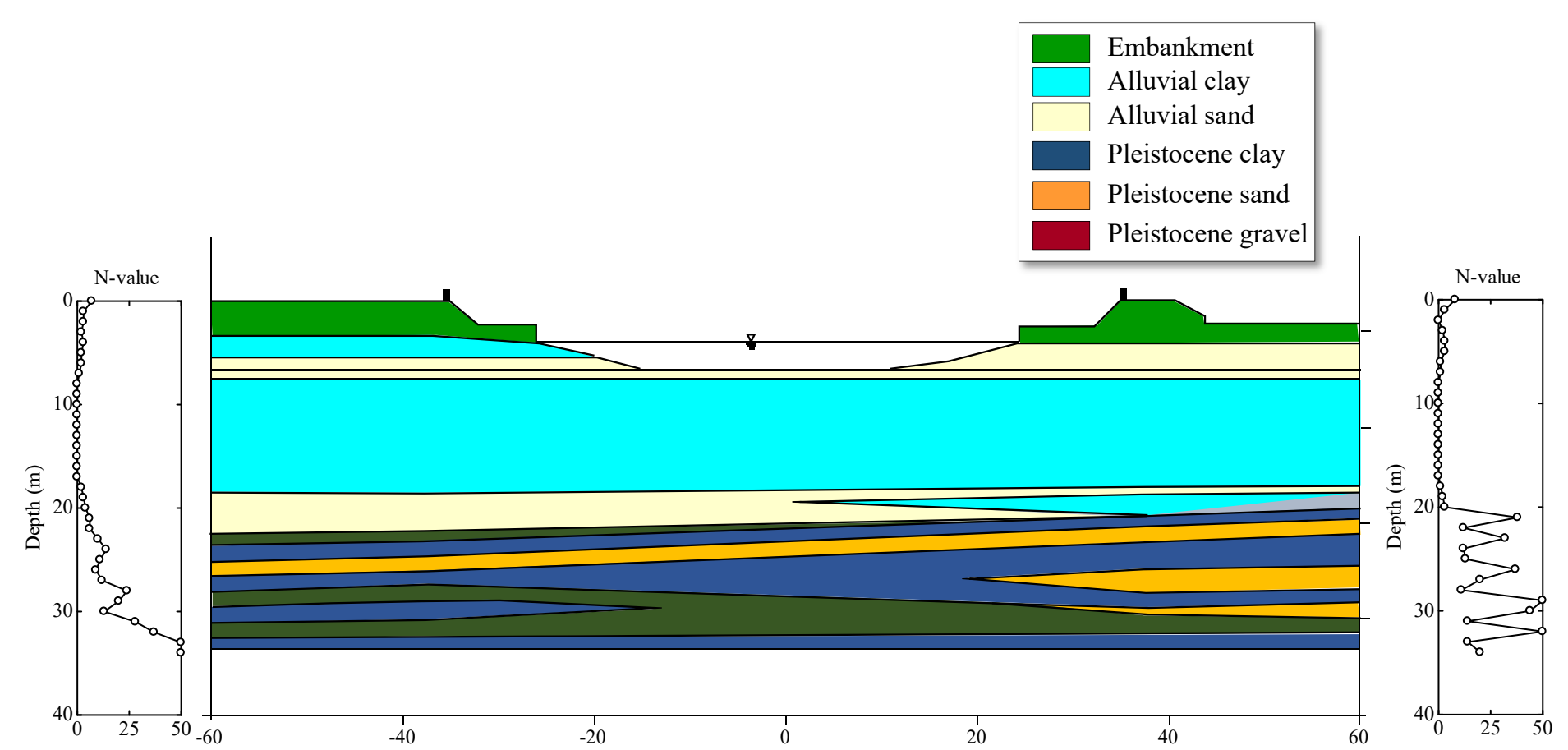




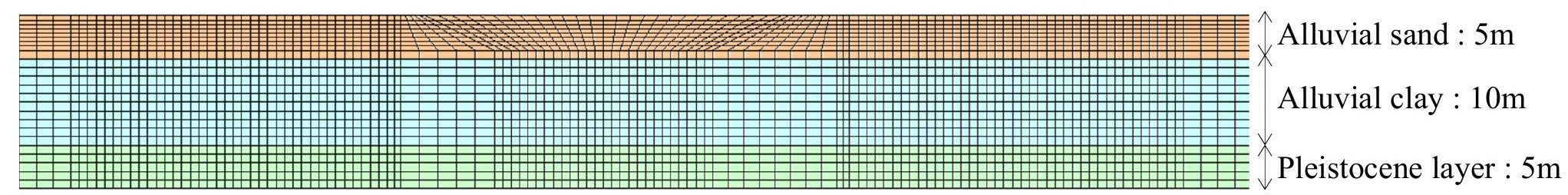

$140 \mathrm{~m}$

Enlargement

$1,000 \mathrm{~m}$ 


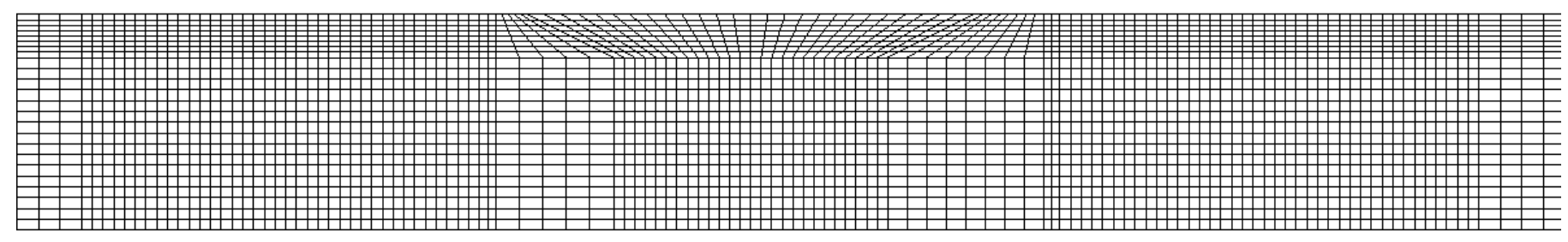

1) Initial foundation

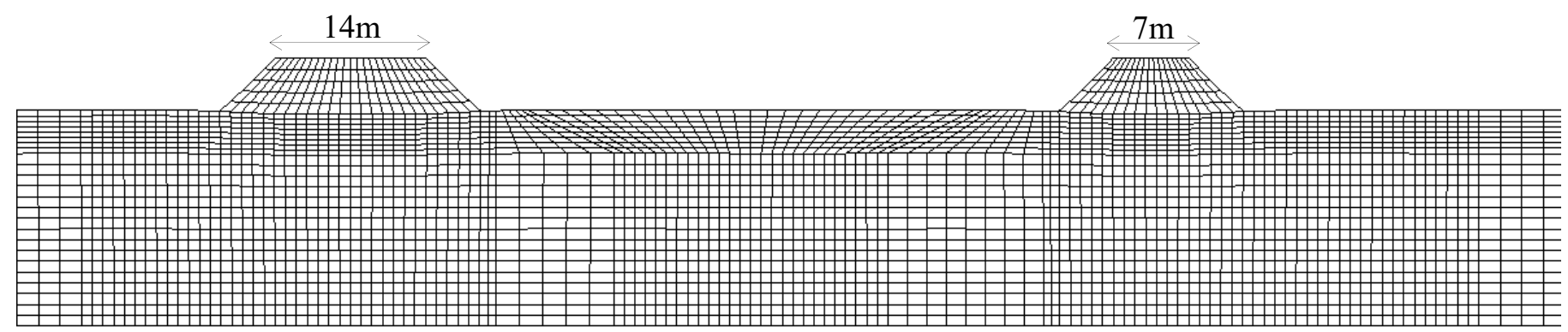

2) Construction of the embankments

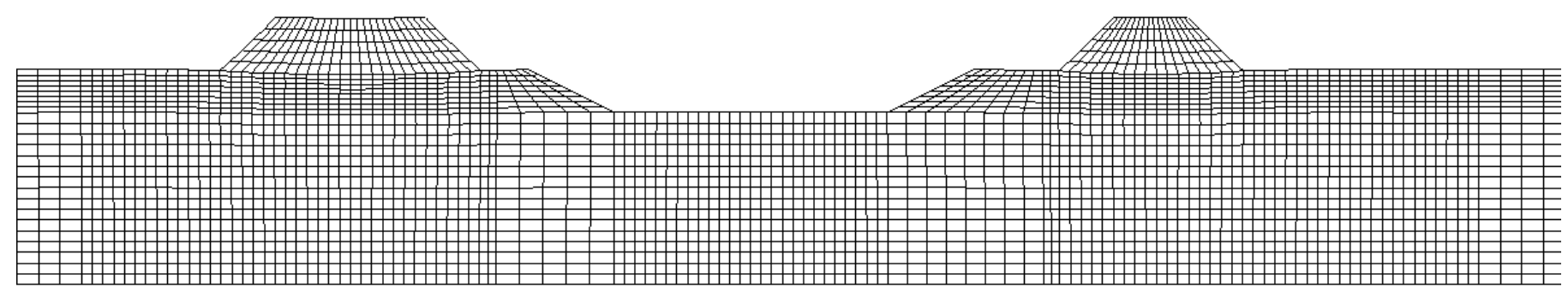

3) Excavation of the river bed

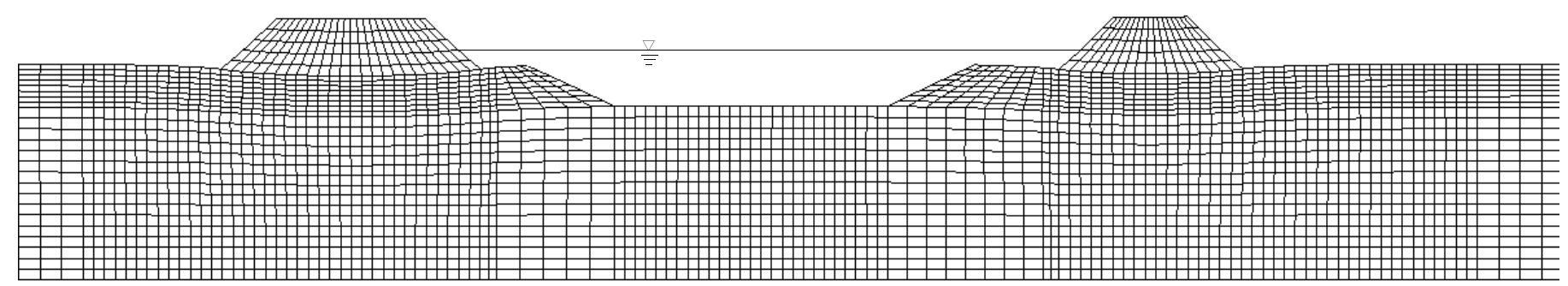

4) Elevation of the water surface to T.P. $1.2 \mathrm{~m}$ and then left for 30 years 


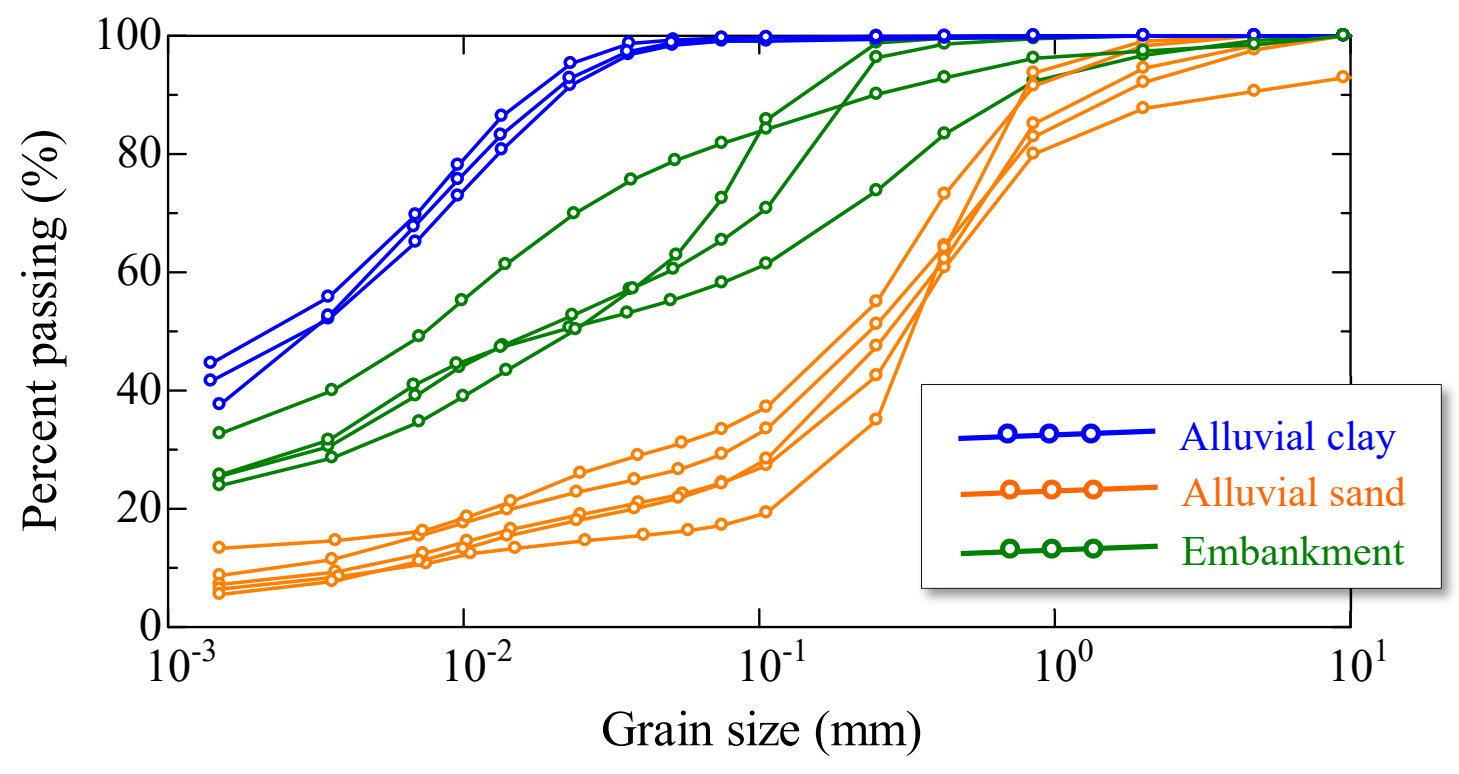



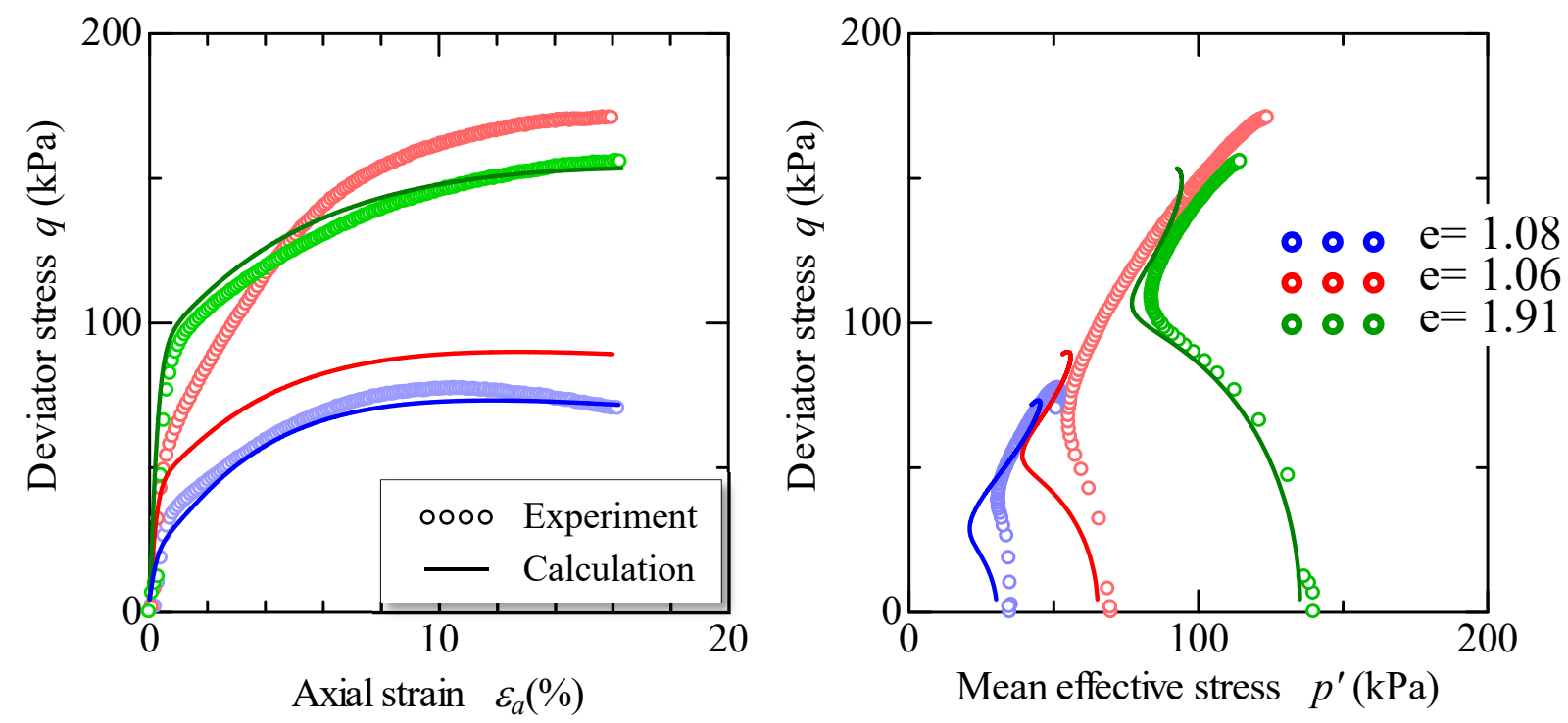

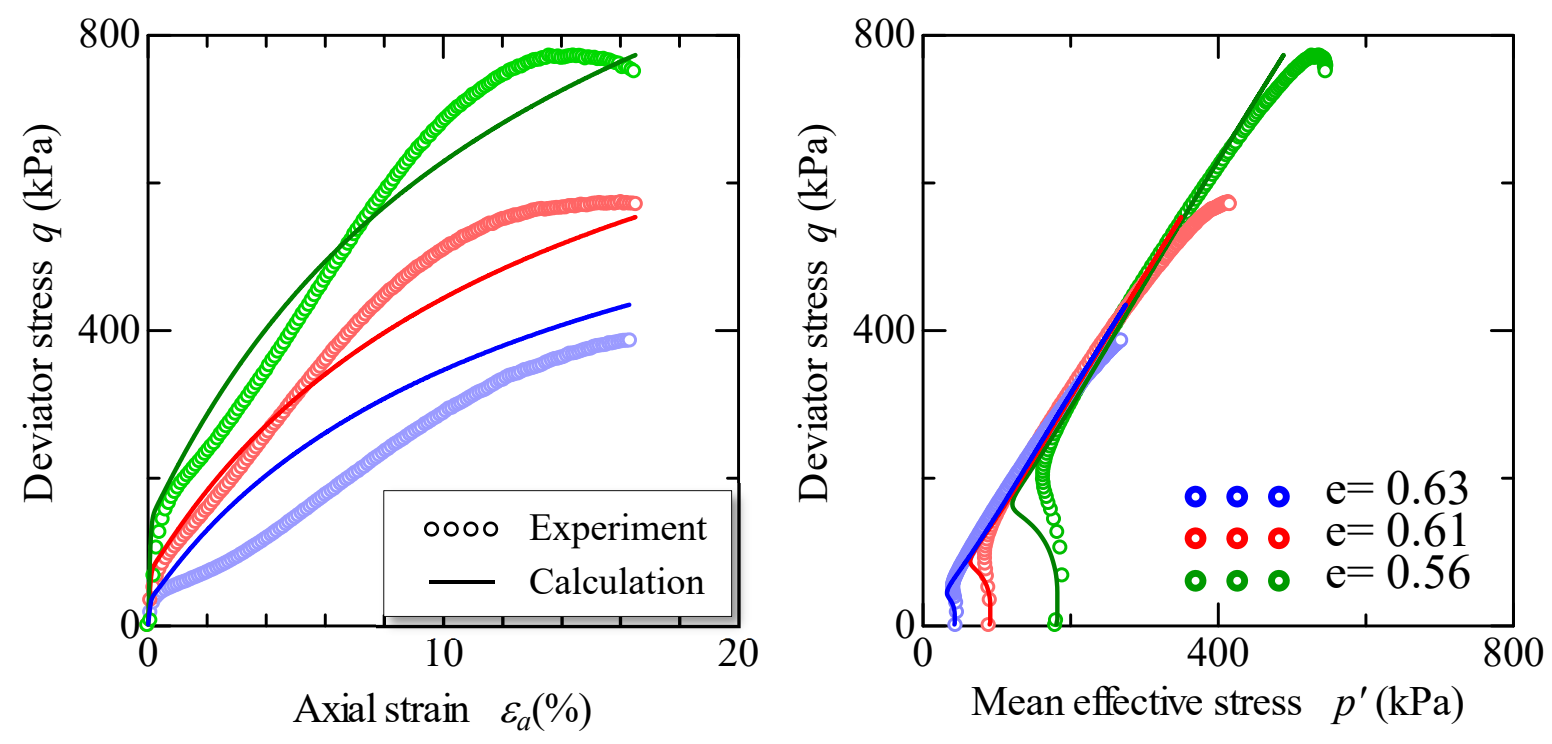


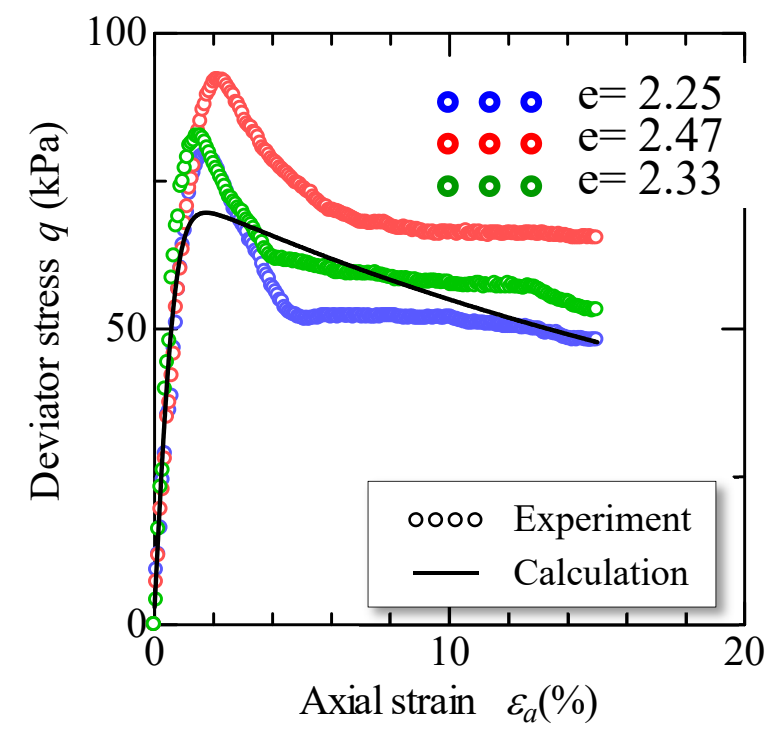

(a) UU test

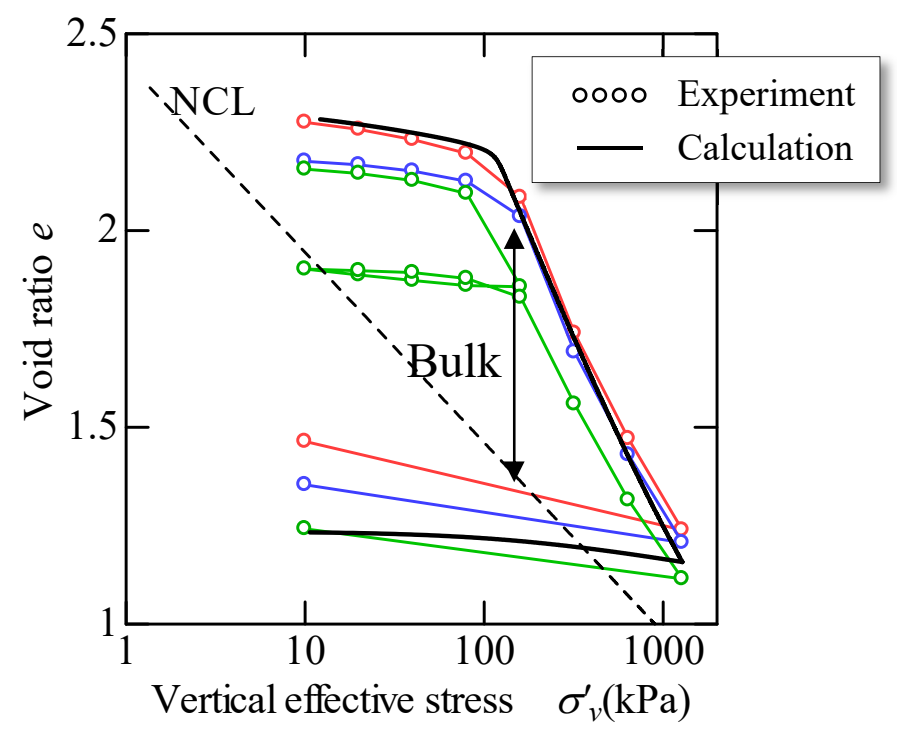

(b) Standard consolidation test 


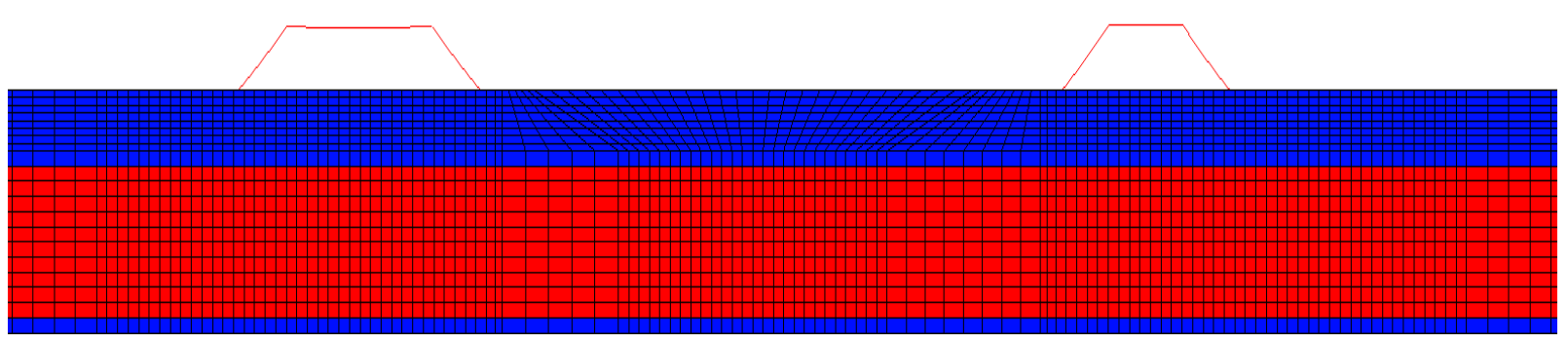

1) Initial foundation

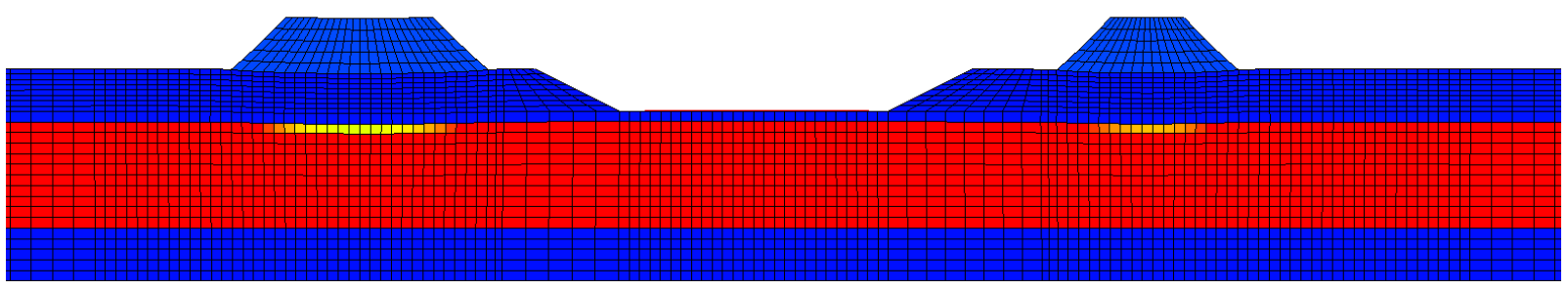

2) Soon after the construction of the river embankment

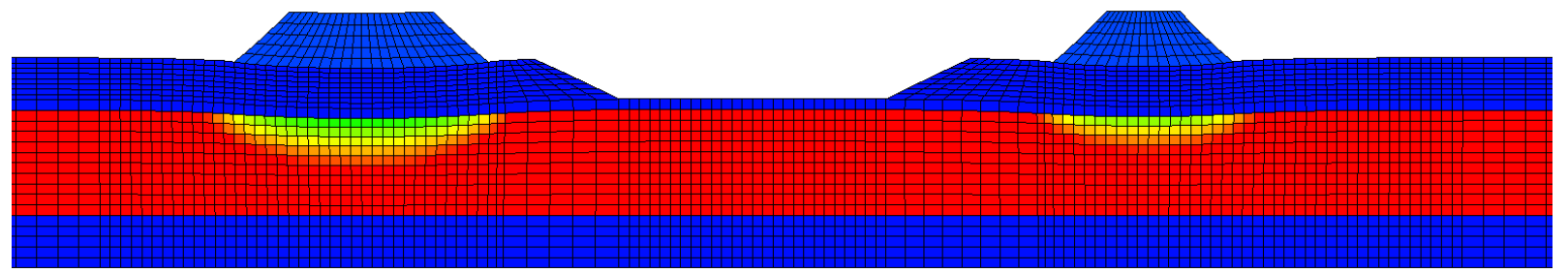

3) 2years after the construction of the river embankment

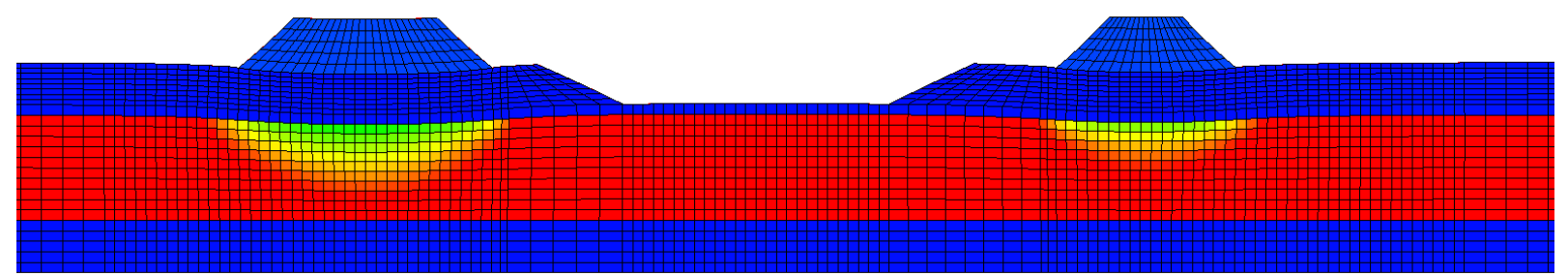

4) 50years after the construction of the river embankment (after the consolidation converges)

1

(Less structured / remolded)
Over 50

(Highly structured) 


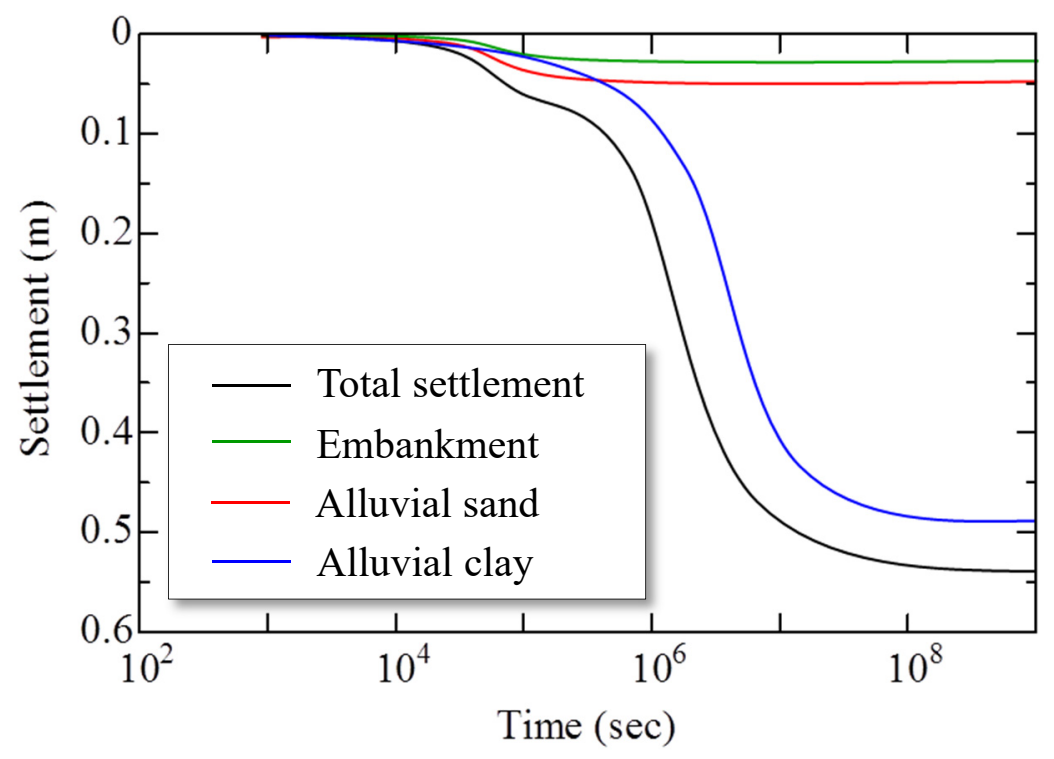




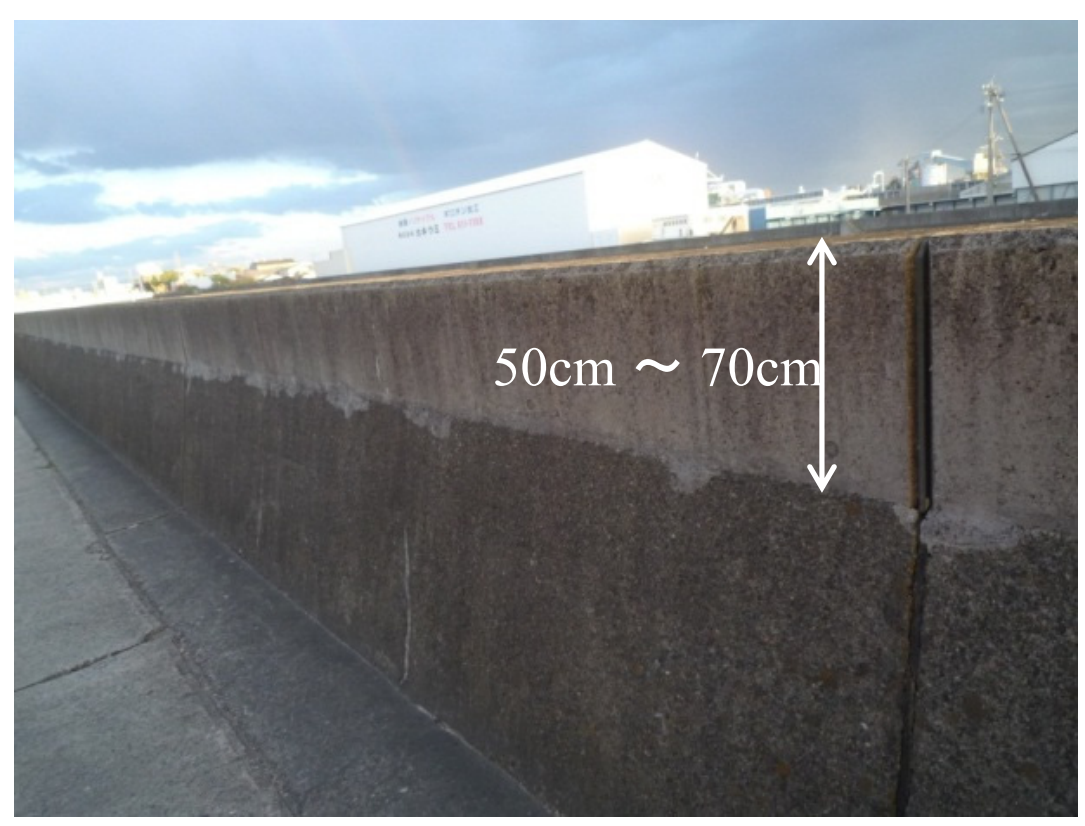




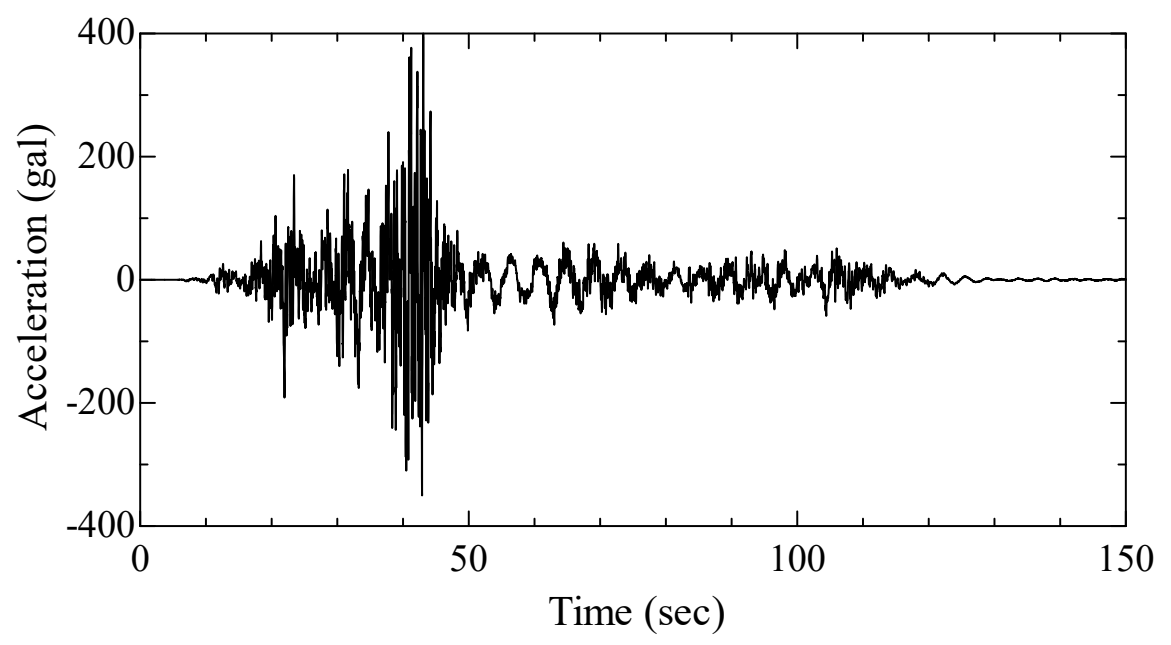




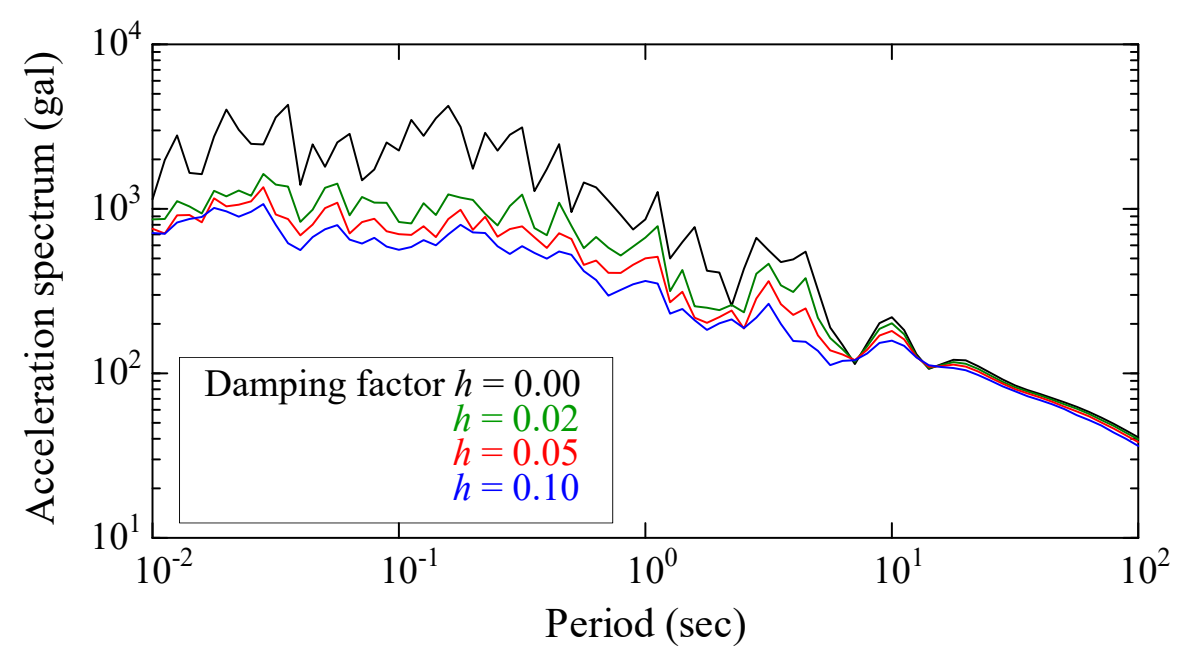




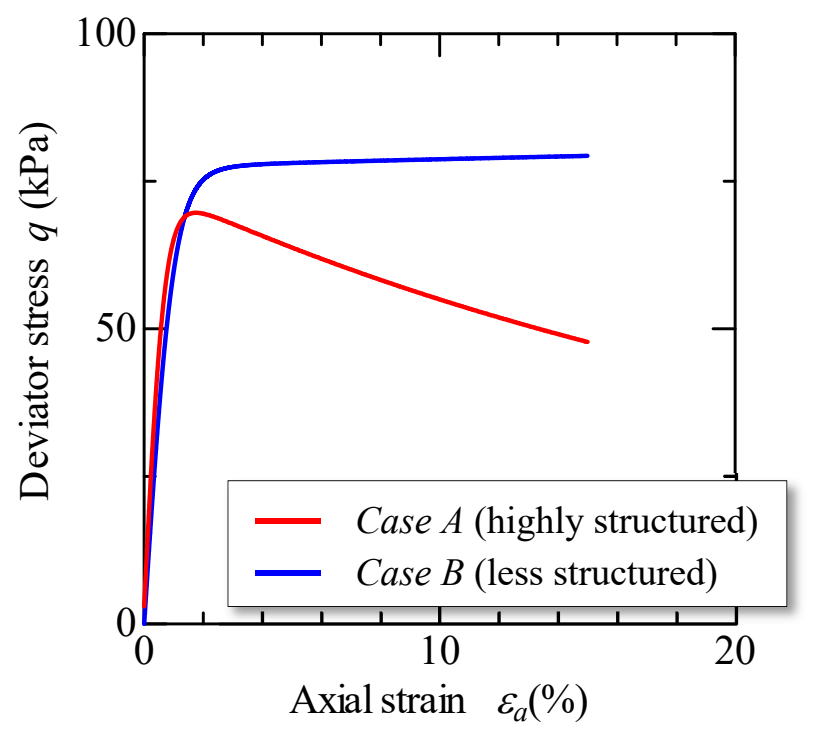

(a) UU test

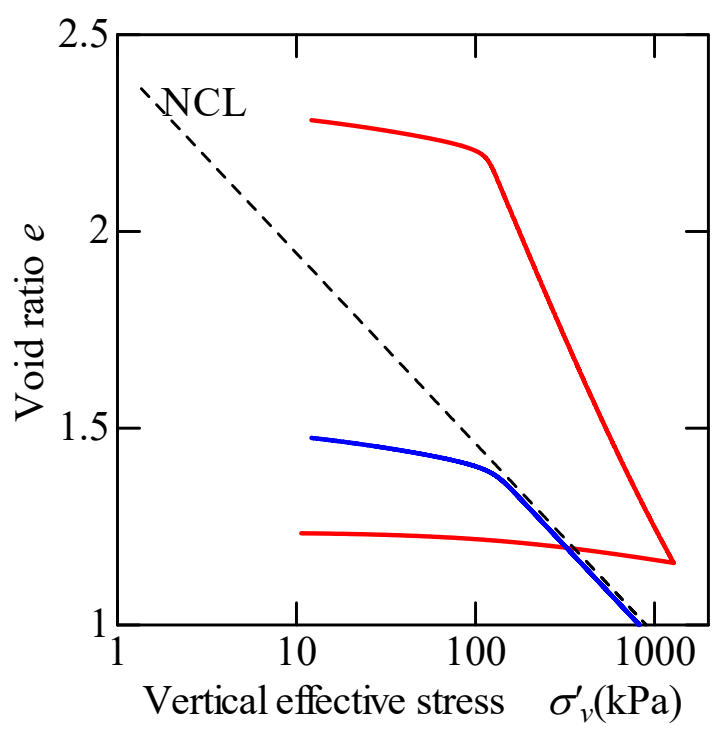

(b) Standard consolidation test 


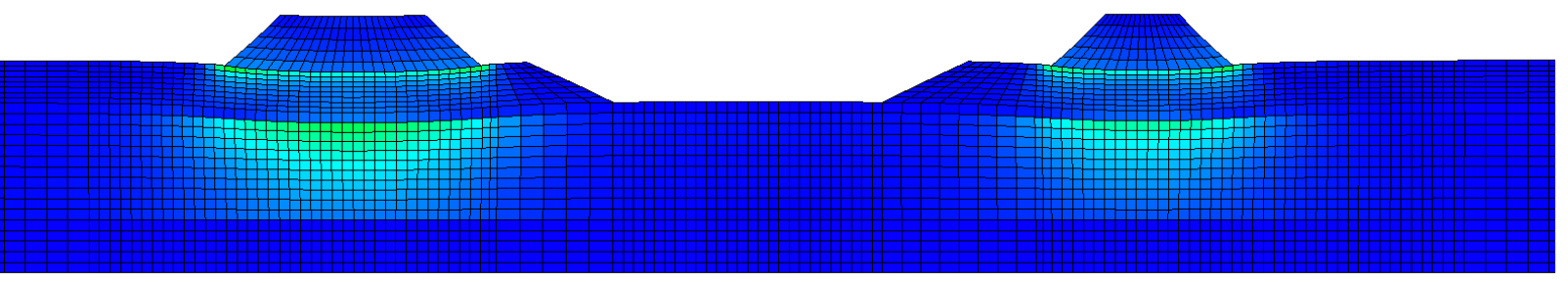

1) Before the occurrence of an earthquake

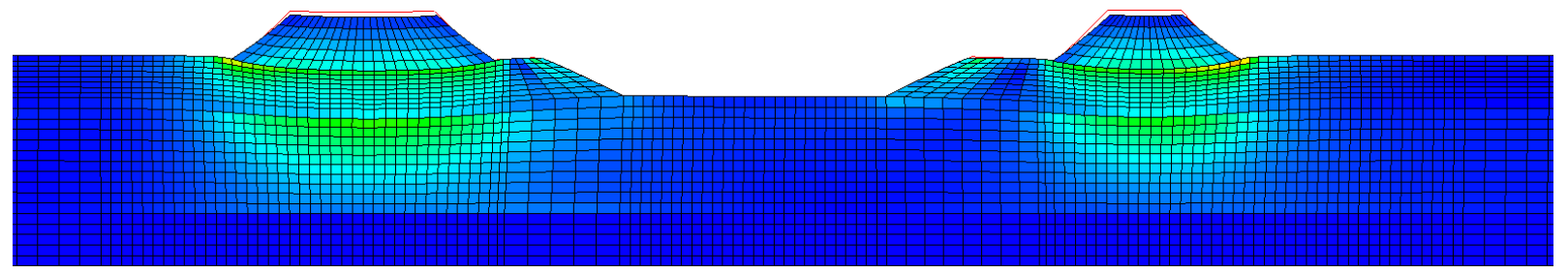

2) $30 \mathrm{~s}$ after the occurrence of an earthquake

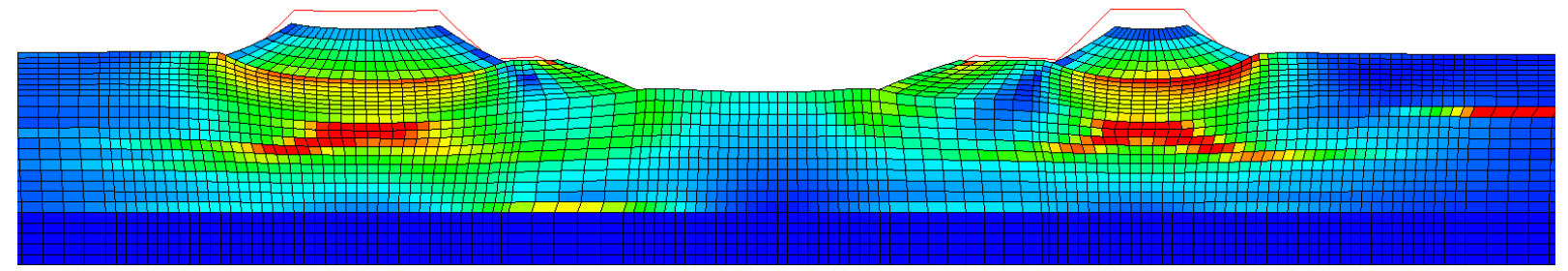

3) $60 \mathrm{~s}$ after the occurrence of an earthquake (around the main shock)

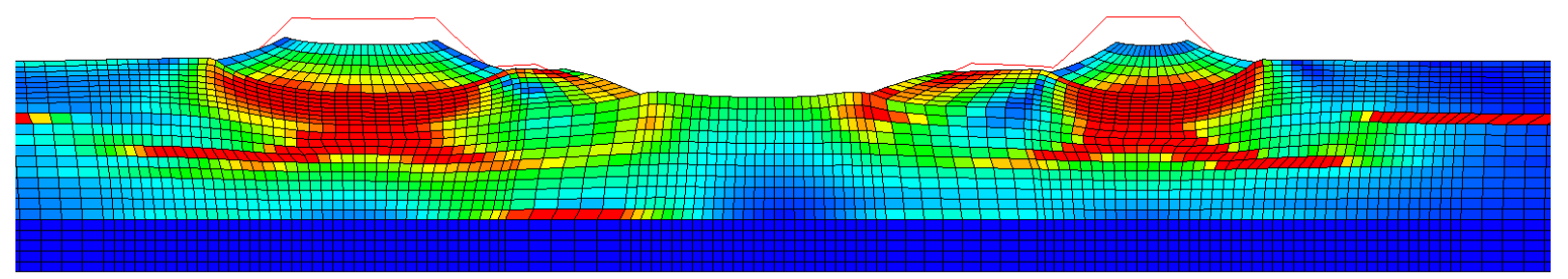

4) $180 \mathrm{~s}$ after the occurrence of an earthquake (soon after the end of an earthquake)

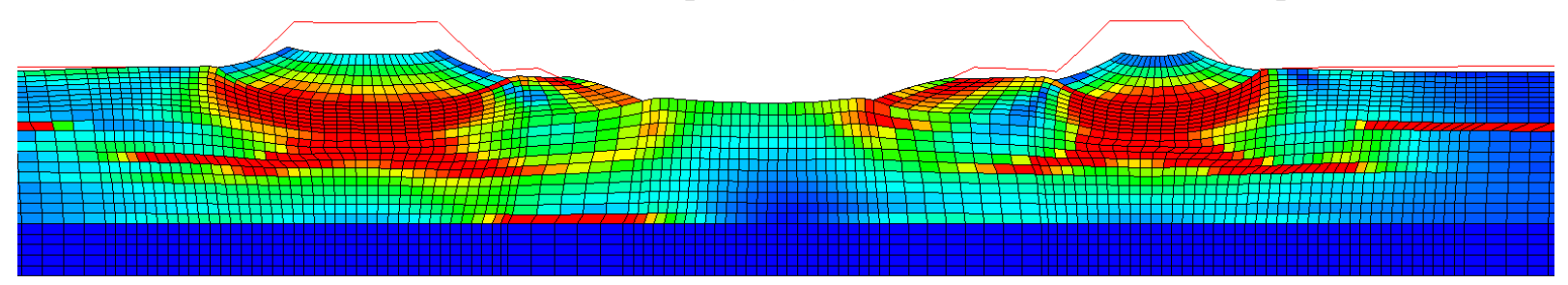

5) 30 years after the occurrence of an earthquake (after the consolidation converges)

$0.0 \%$ Over $30.0 \%$ 


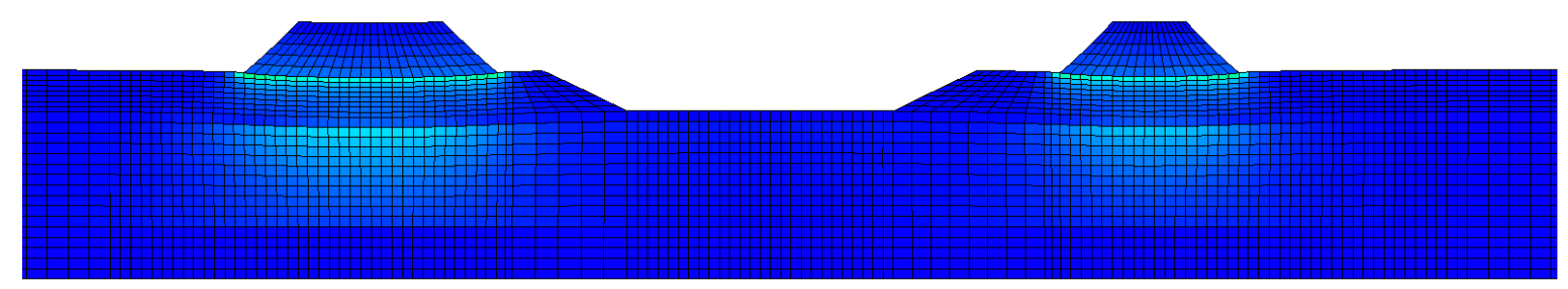

1) Before the occurrence of an earthquake

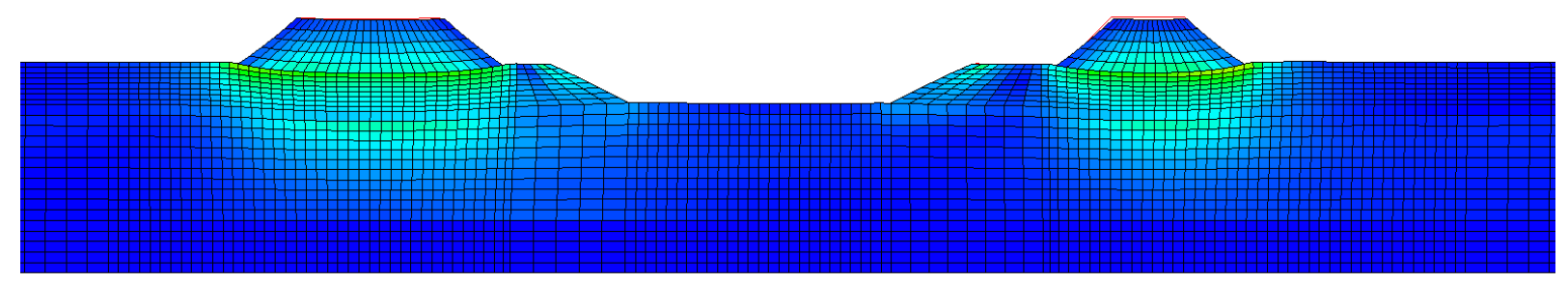

2) $30 \mathrm{~s}$ after the occurrence of an earthquake

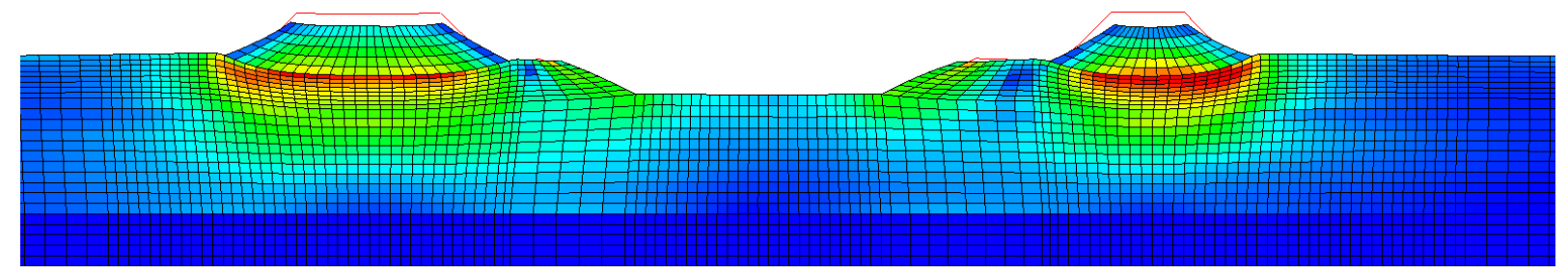

3) $60 \mathrm{~s}$ after the occurrence of an earthquake (around the main shock)

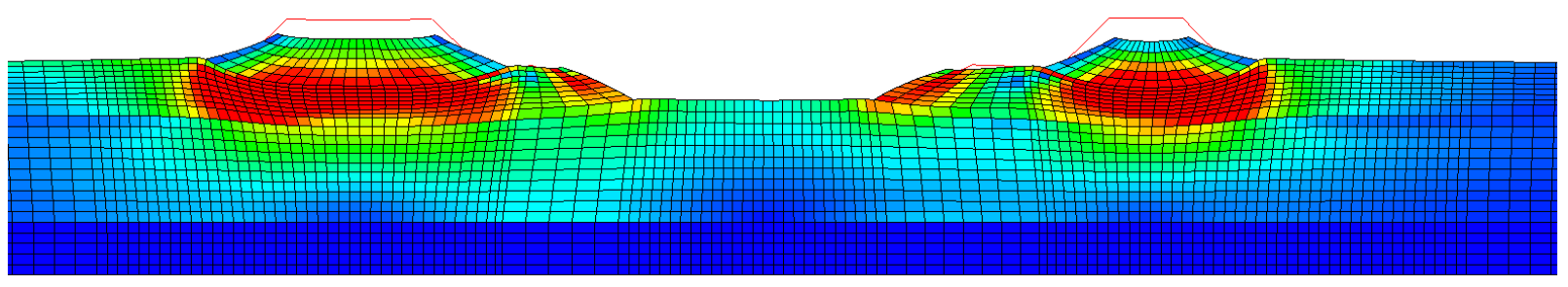

4) $180 \mathrm{~s}$ after the occurrence of an earthquake (soon after the end of an earthquake)

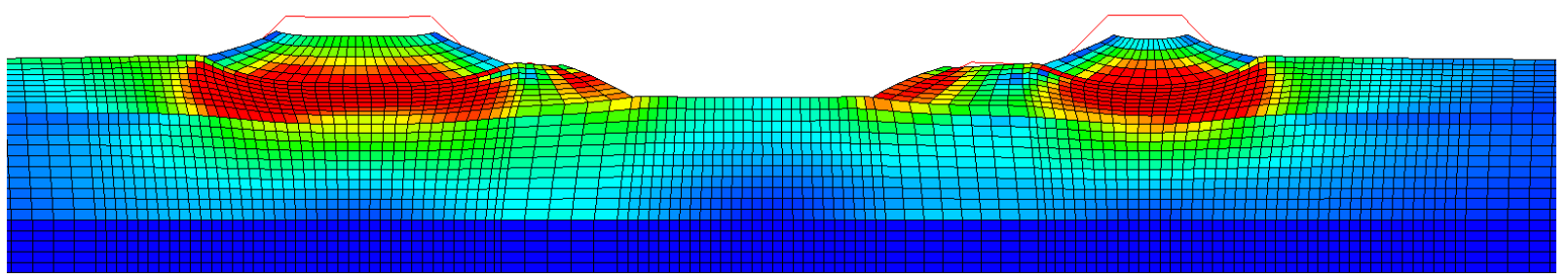

5) 30 years after the occurrence of an earthquake (after the consolidation converges)

$$
0.0 \%
$$

Over $30.0 \%$ 


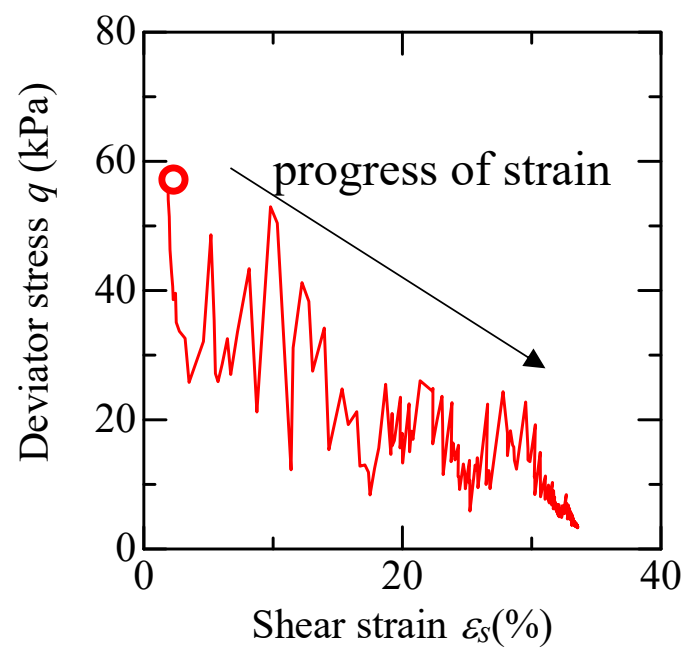

(a)

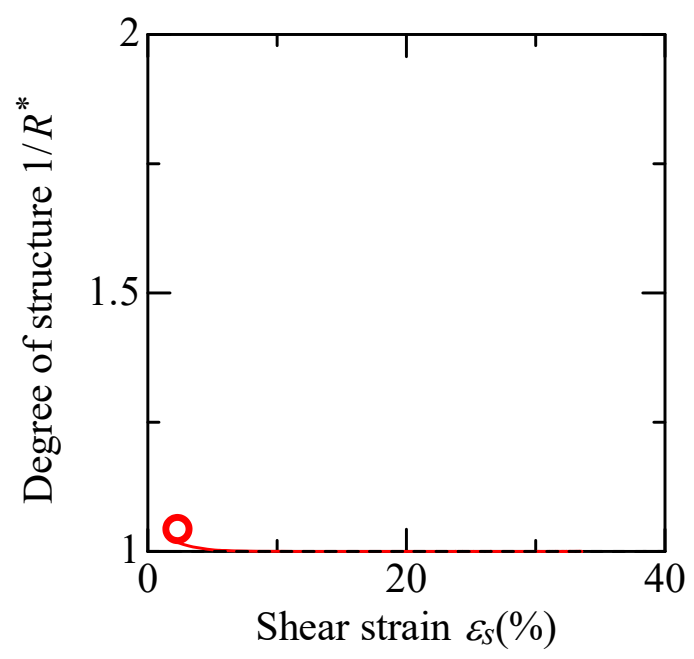

(c)

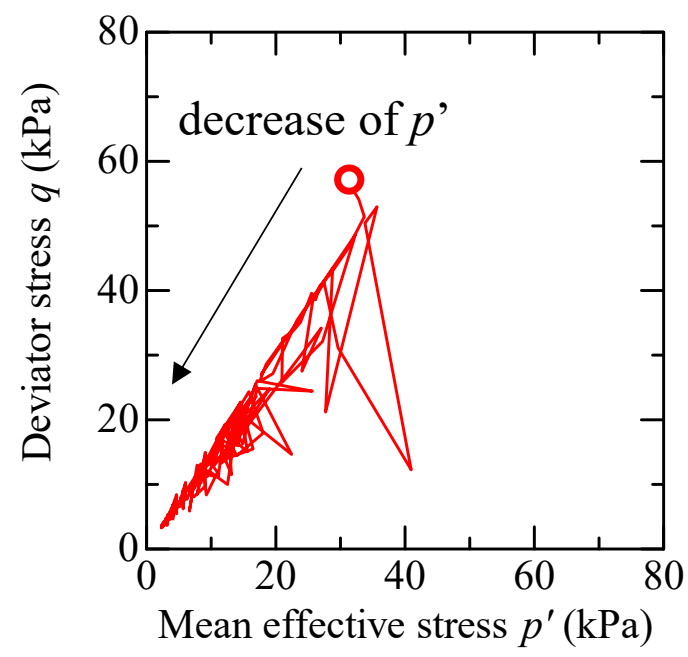

(b)

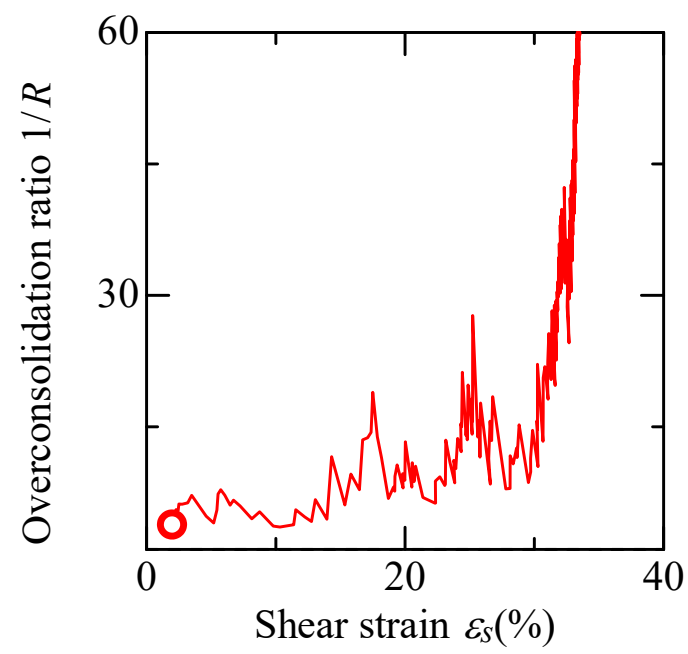

(d) 


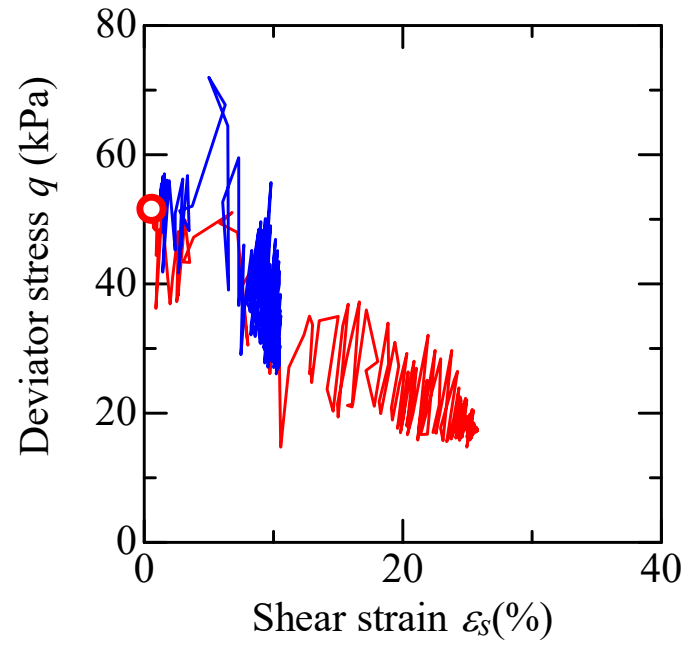

(a)

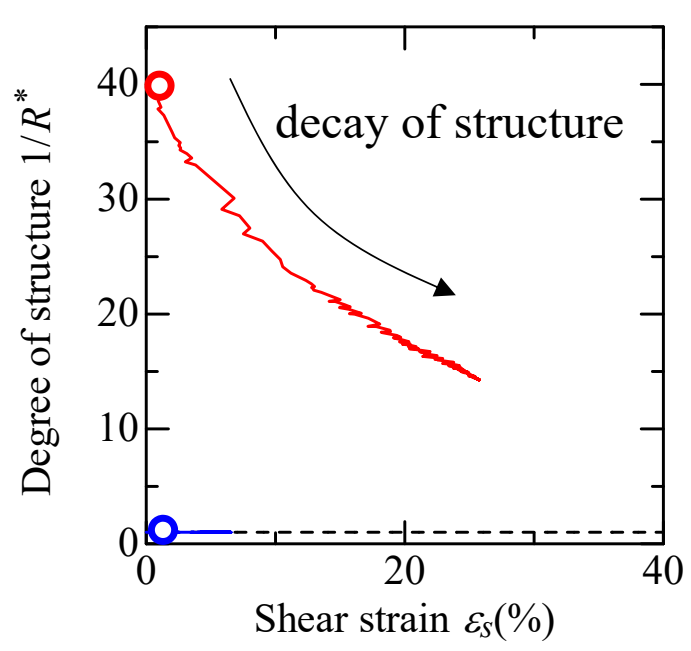

(c)

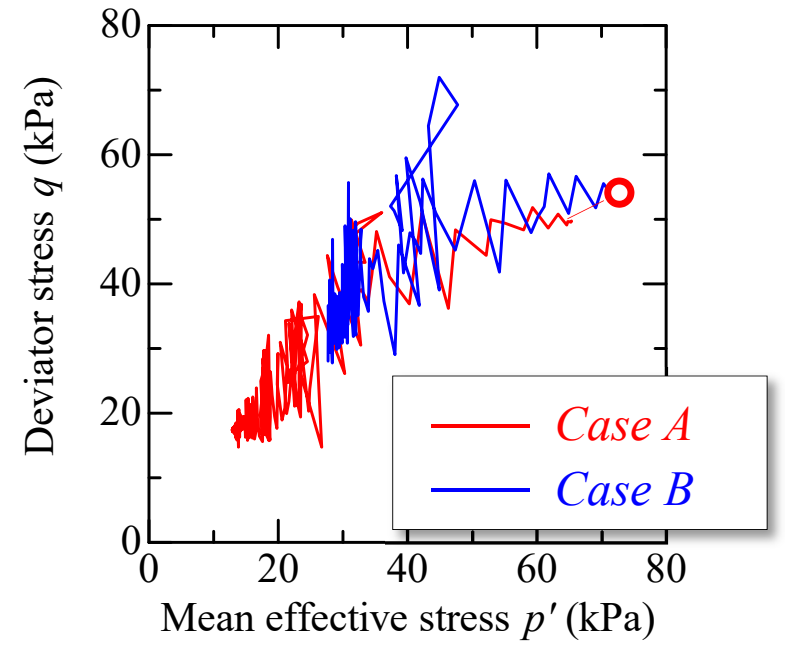

(b)

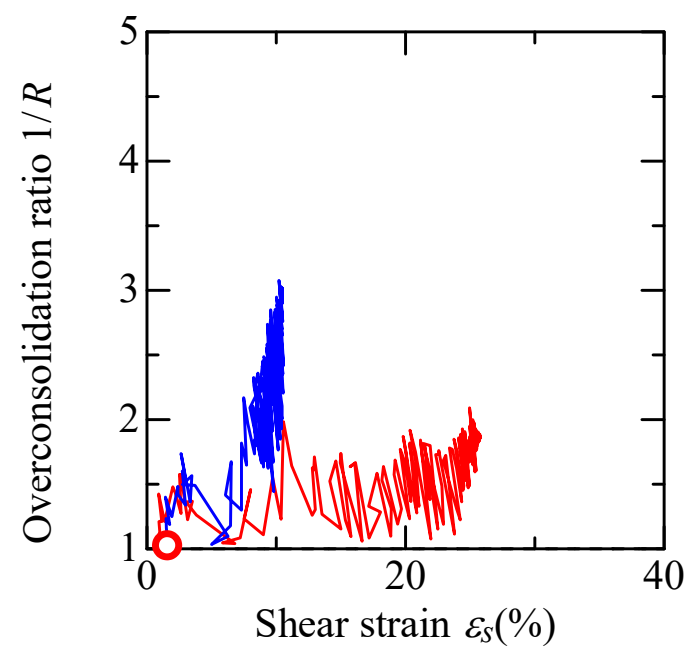

(d) 


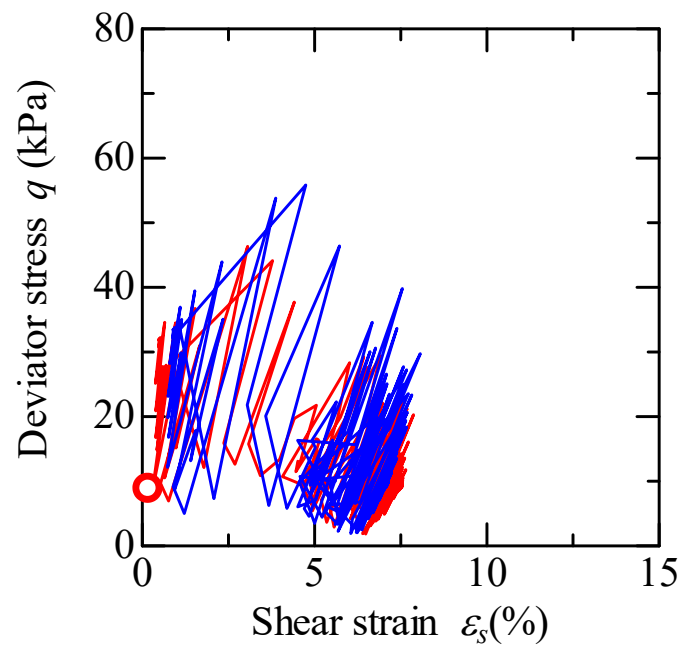

(a)

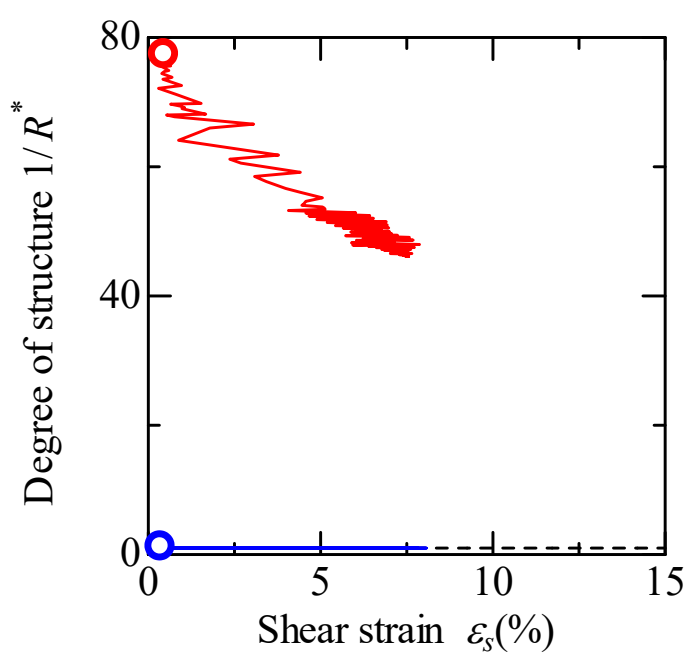

(c)

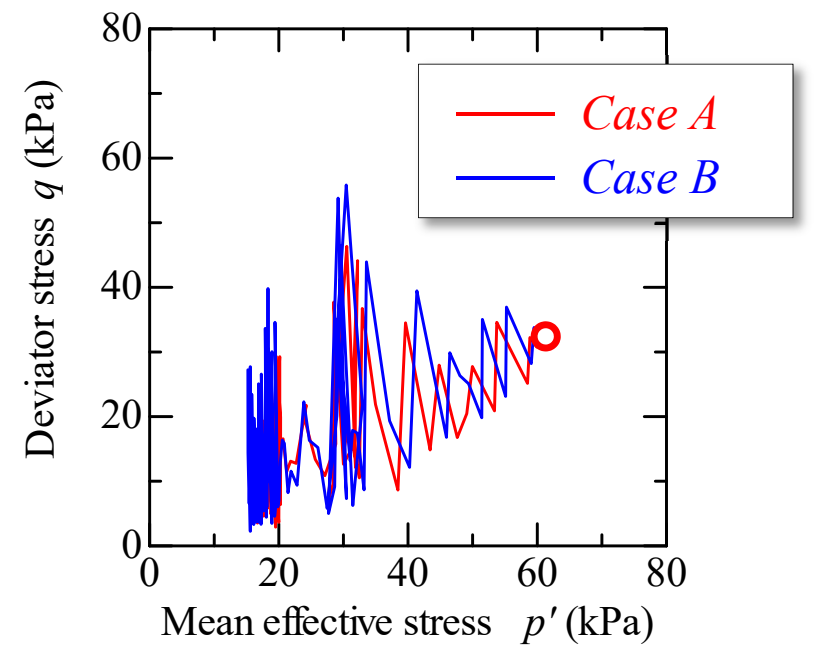

(b)

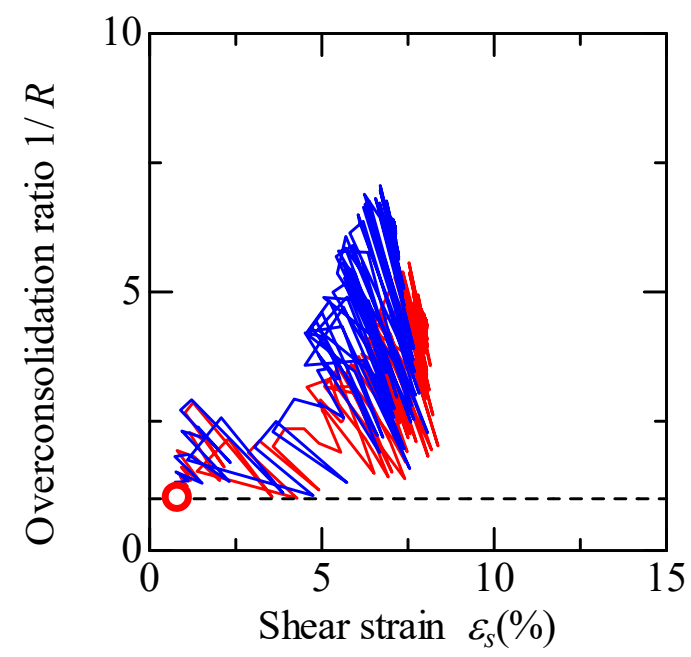

(d) 


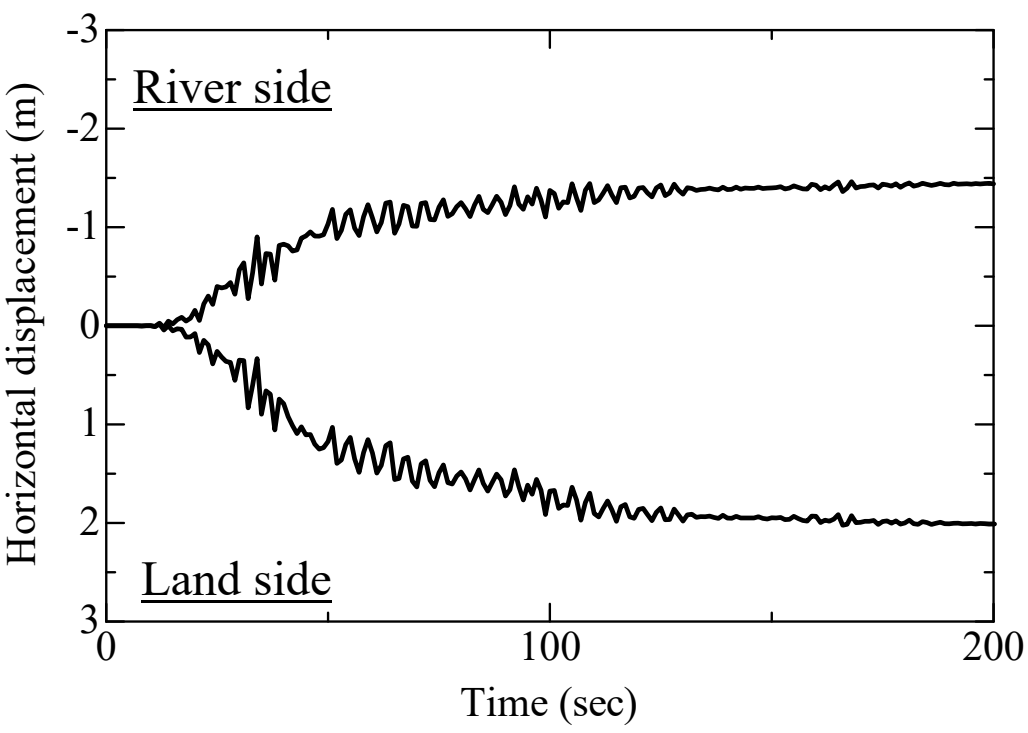

(a) Case A

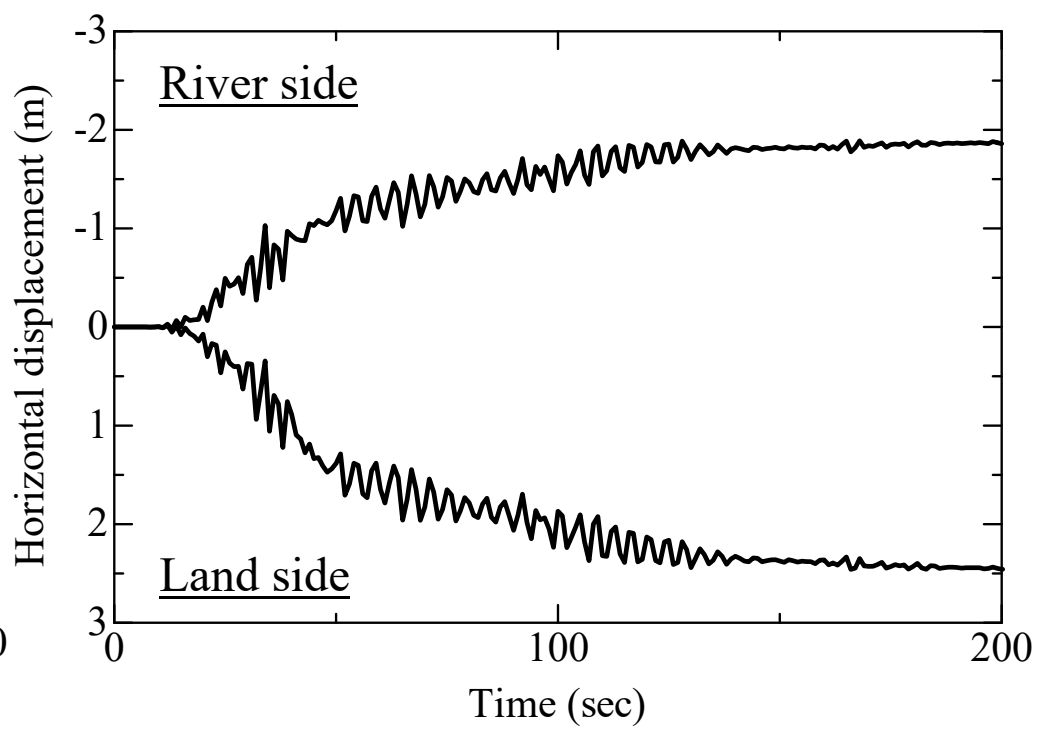

(b) Case B 
$\underline{\text { Land side }}$

$\underline{\text { River side }}$






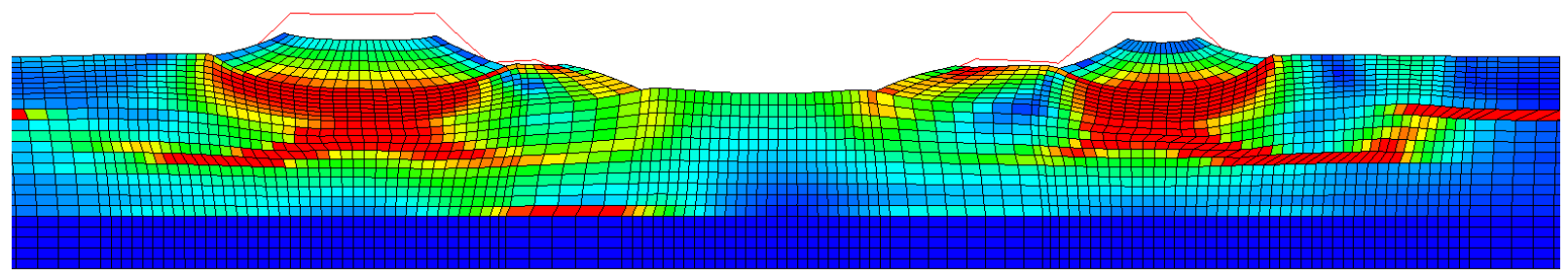

Case A: Without steel pipe sheet piles

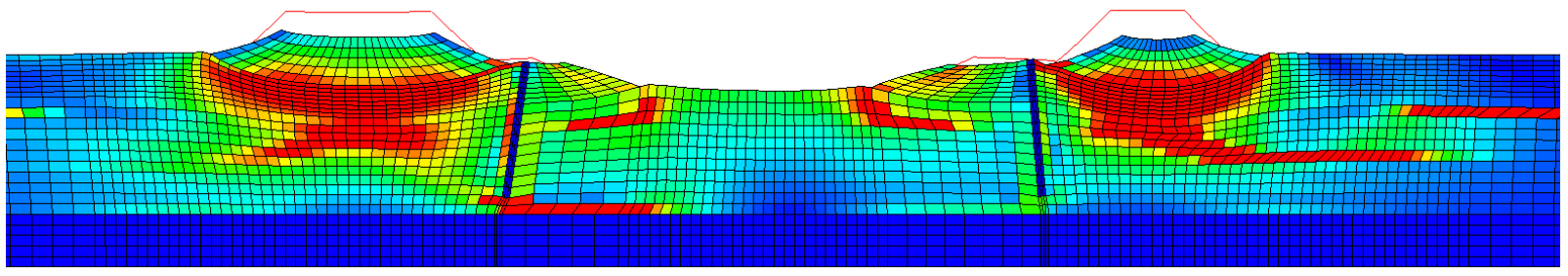

Case A_1: Only river side with short sheet piles

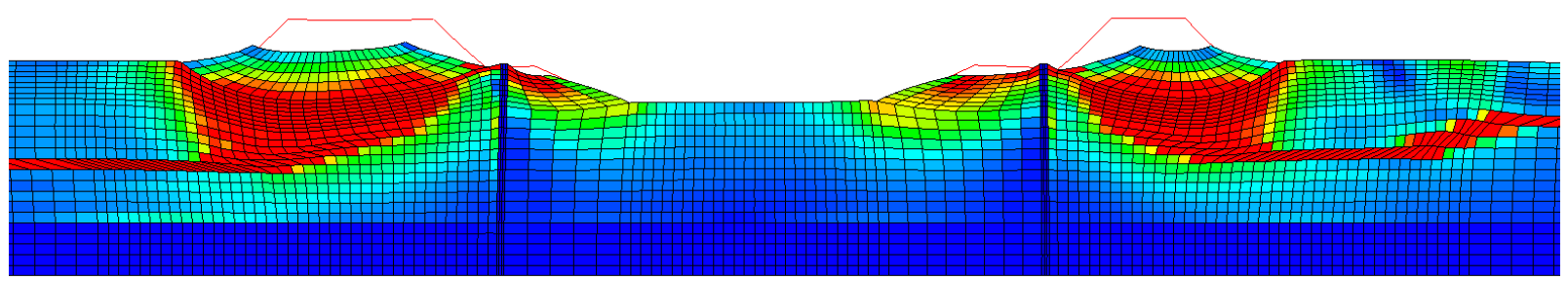

Case A_2: Only river side with long sheet piles

$0.0 \%$

Over $30.0 \%$ 


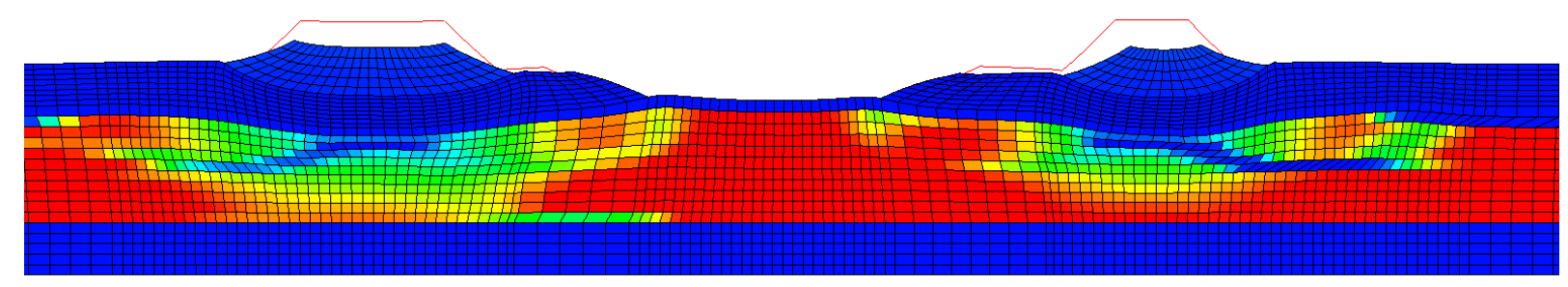

Case A: Without steel pipe sheet piles

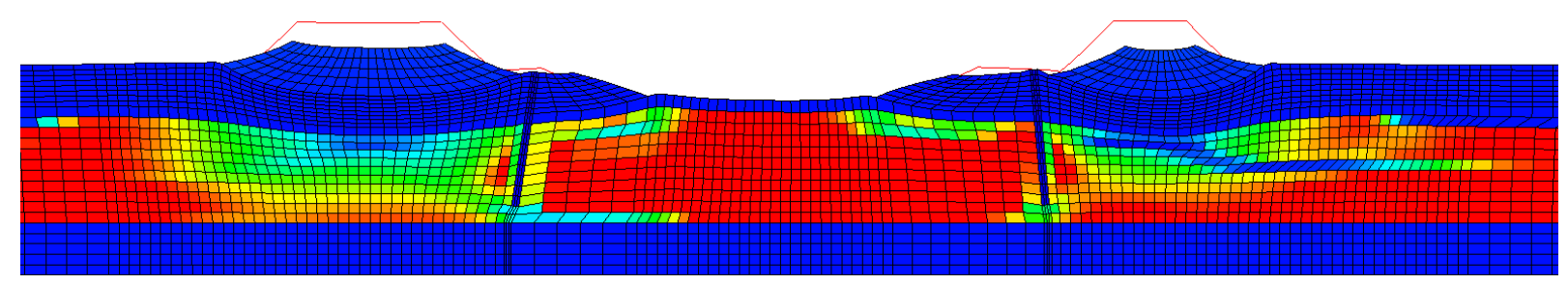

Case A_1: Only river side with short sheet piles

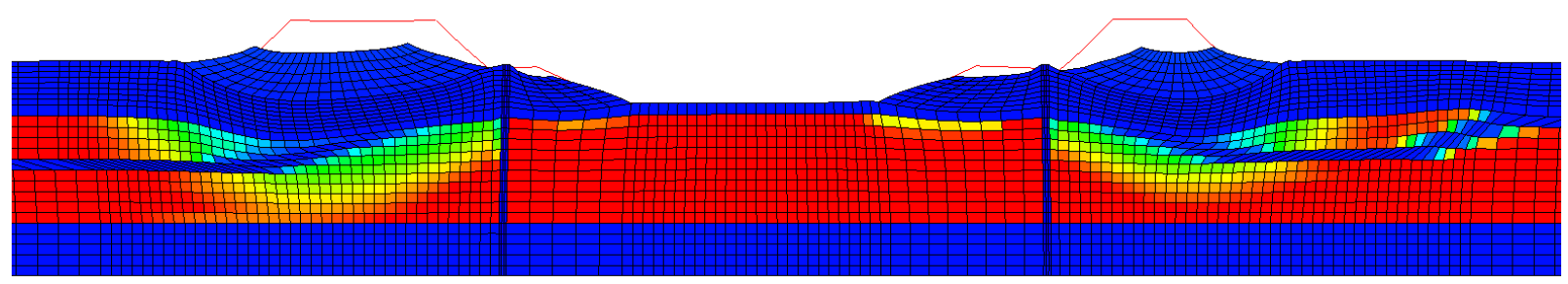

Case A_2: Only river side with long sheet piles

$\begin{array}{cc}1 & \text { Over } 50 \\ \text { (Less structured / remolded) } & \text { (Highly structured) }\end{array}$




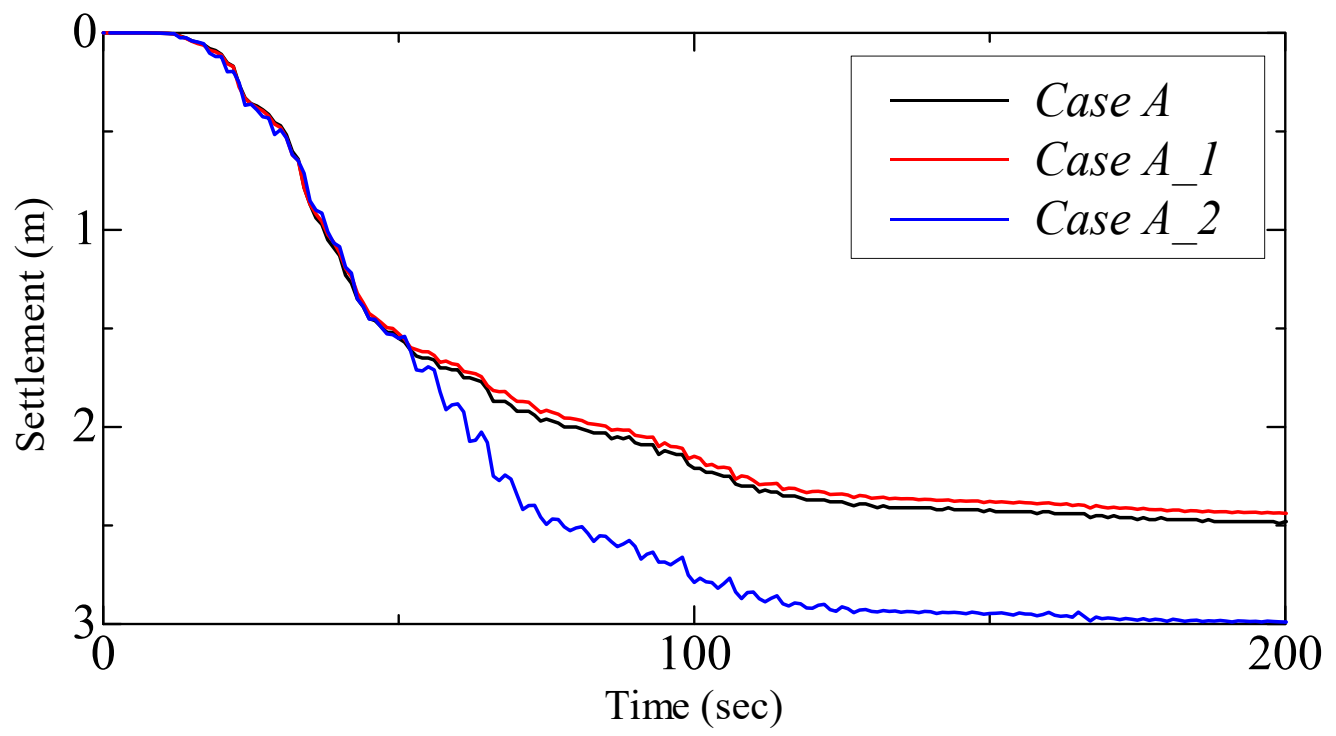

https://mc06.manuscriptcentral.com/cgj-pubs 


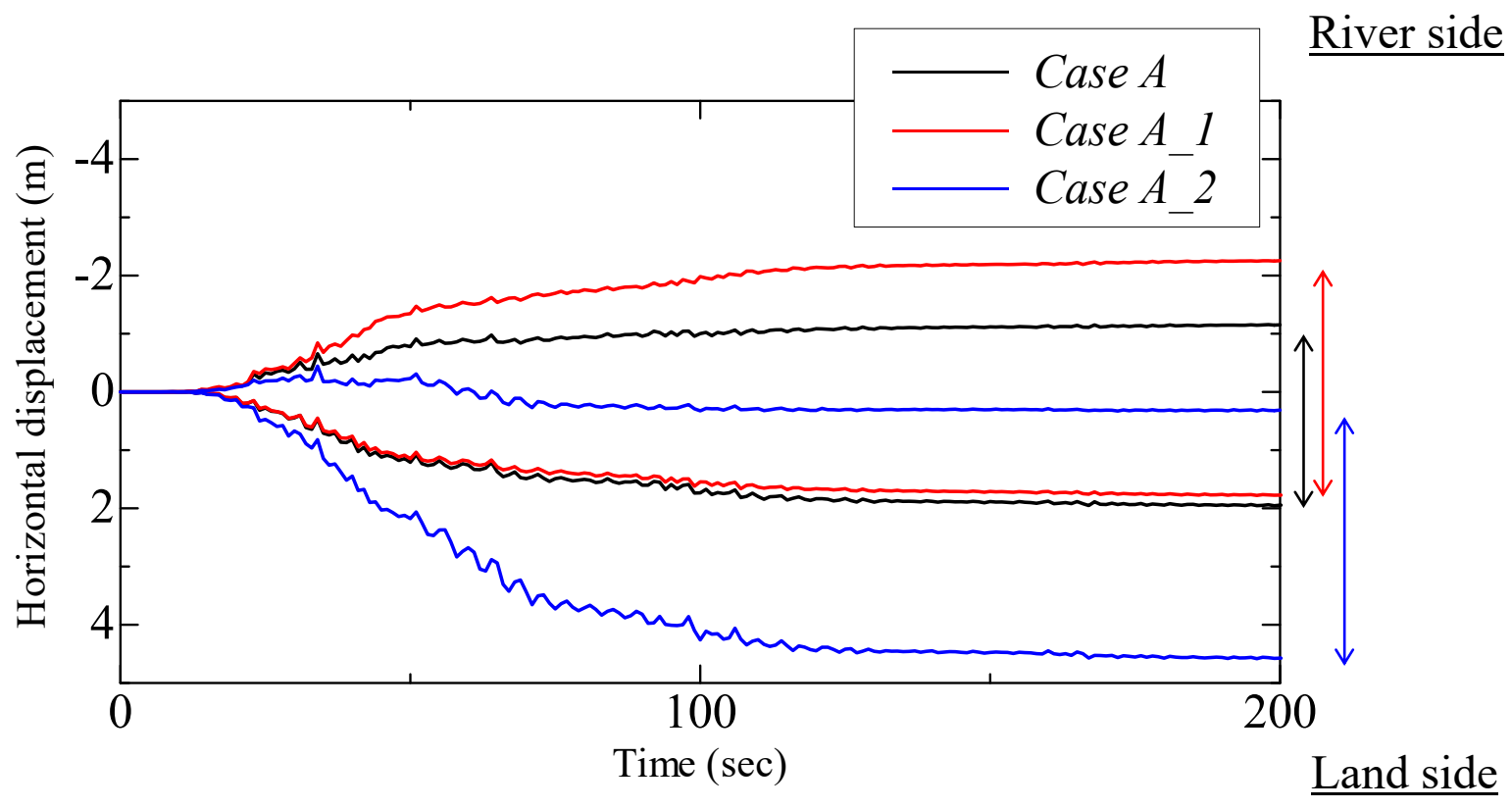



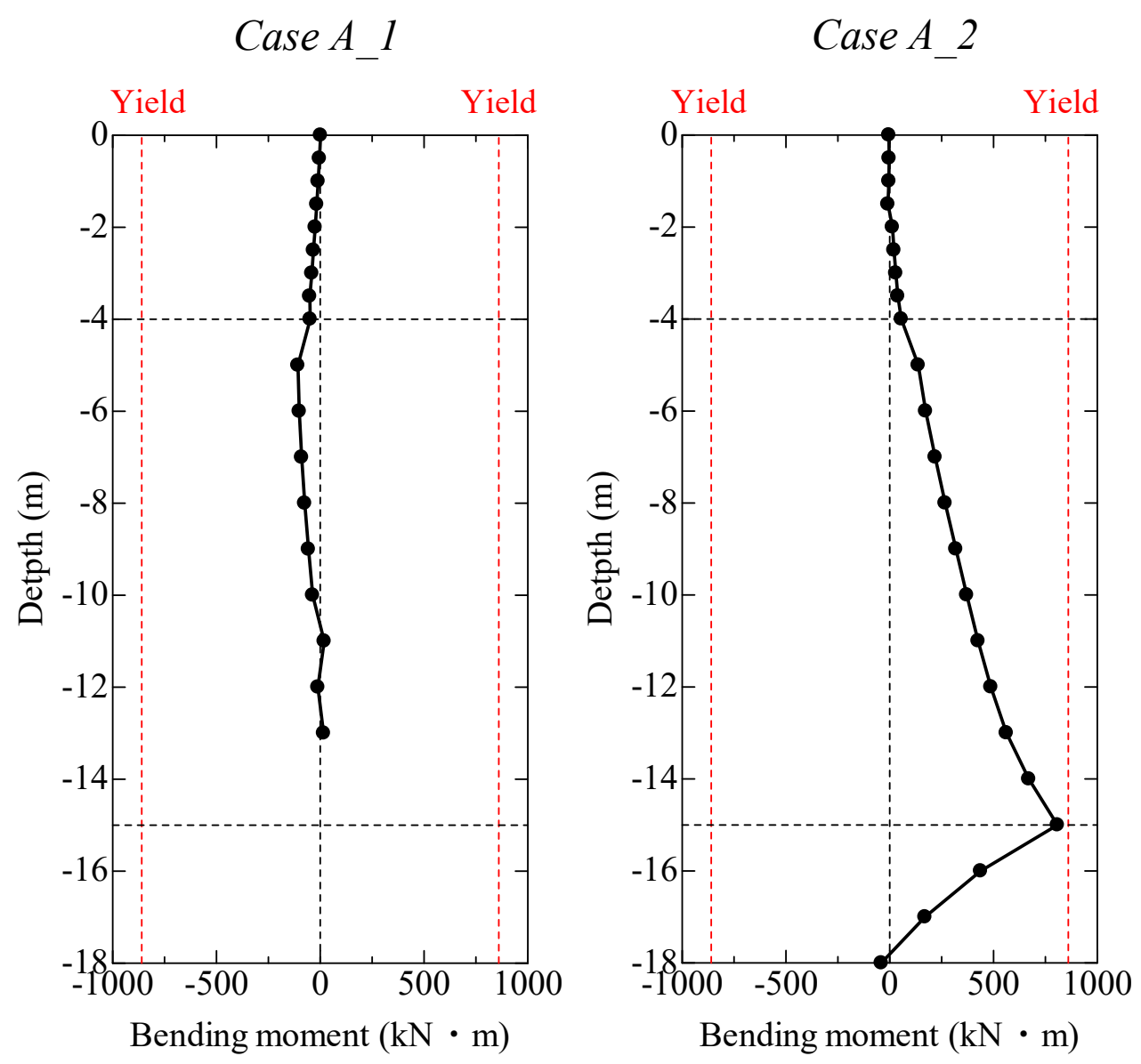


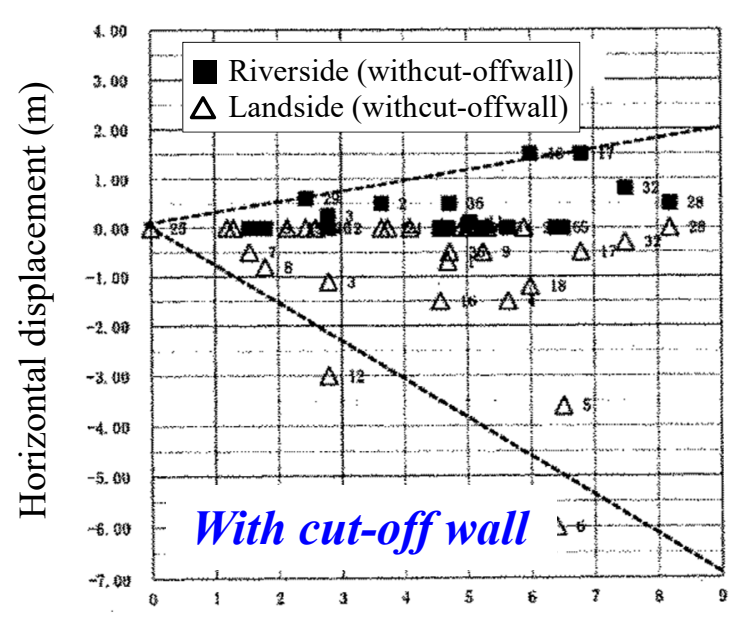

Thickness of the liquefiable layer (m)

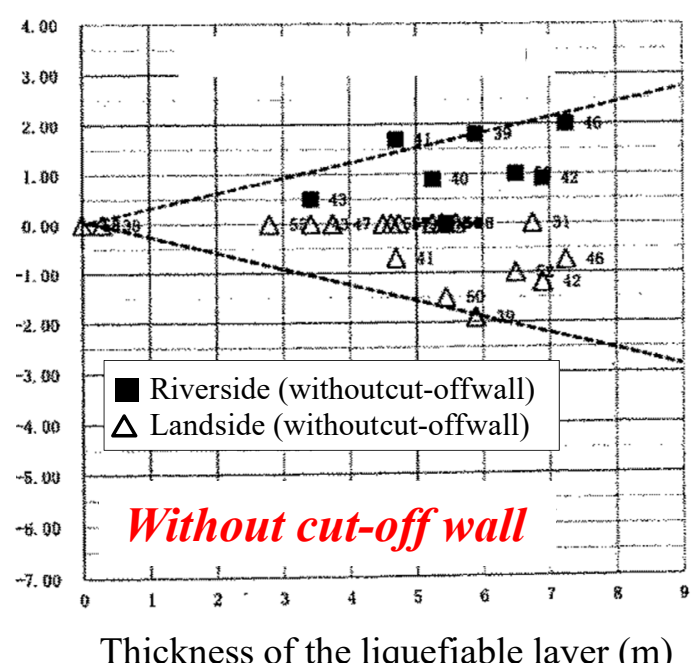

Thickness of the liquefiable layer (m)

(a) Horizontal displacement at both embankment toe
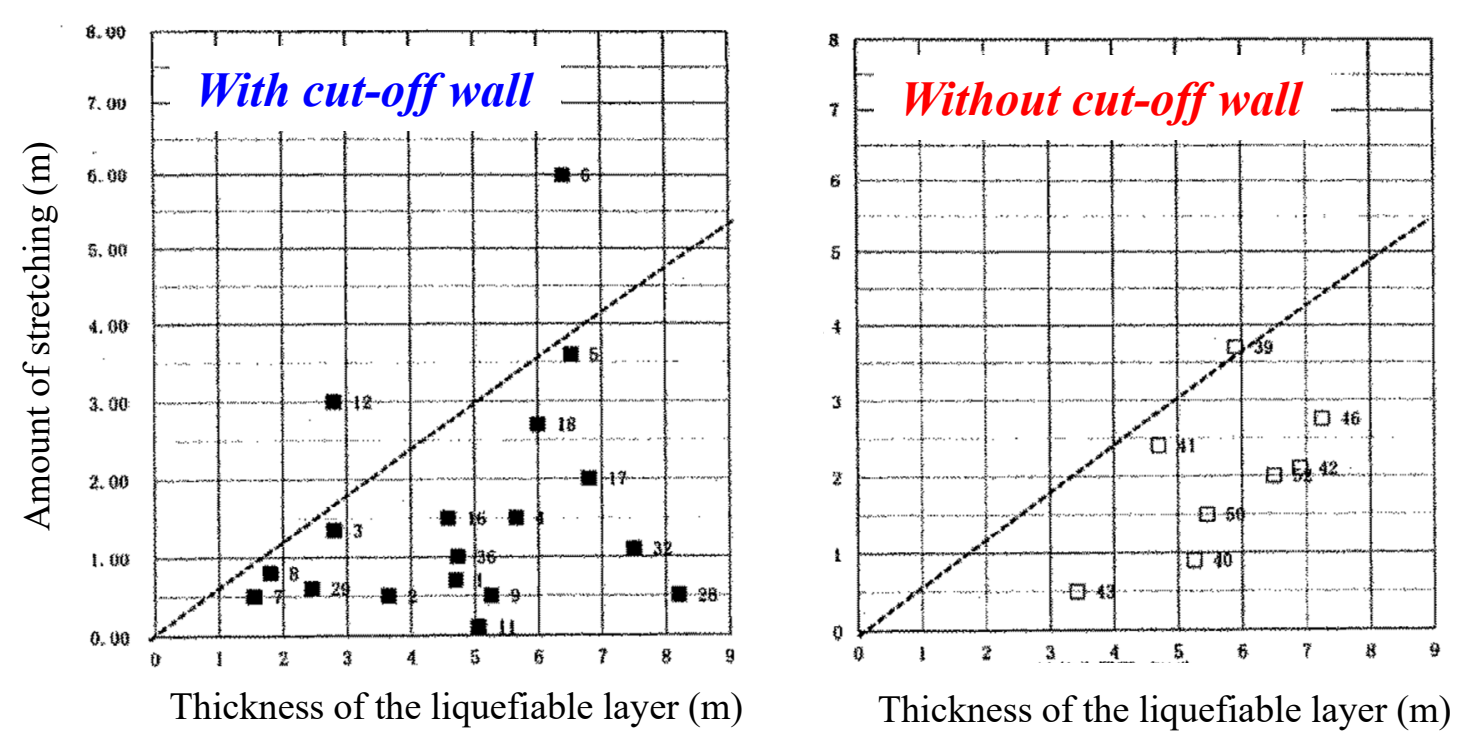

(b) Amount of stretching at the embankment toe 


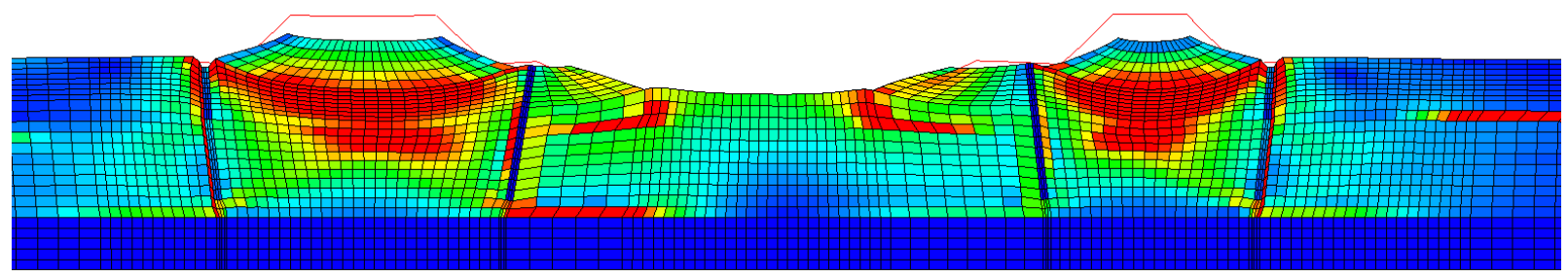

CaseA_3: Both river and land side with short sheet piles

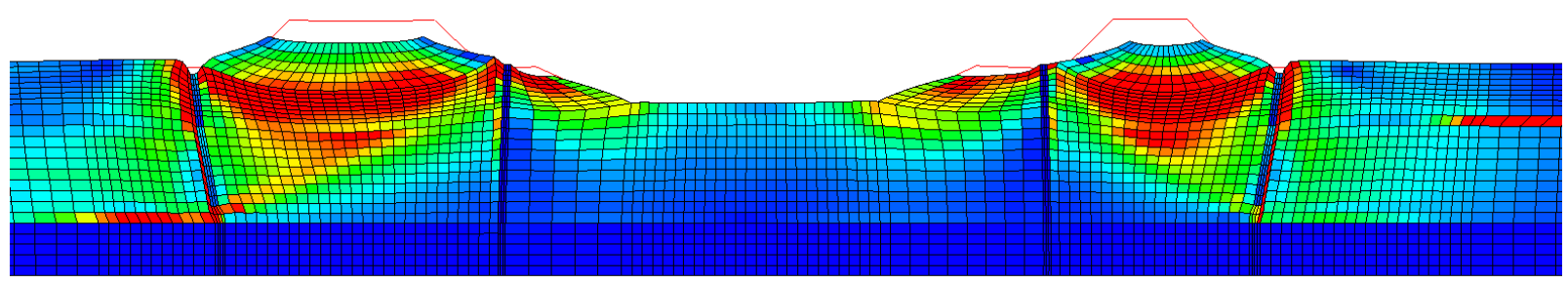

CaseA_4: Short sheet piles at river side and long sheet pile at land side

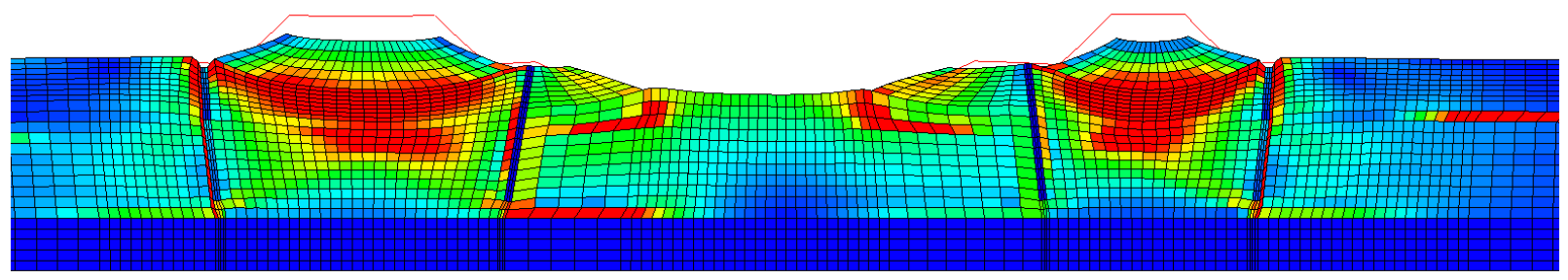

CaseA_5: Long sheet piles at river side and short sheet pile at land side

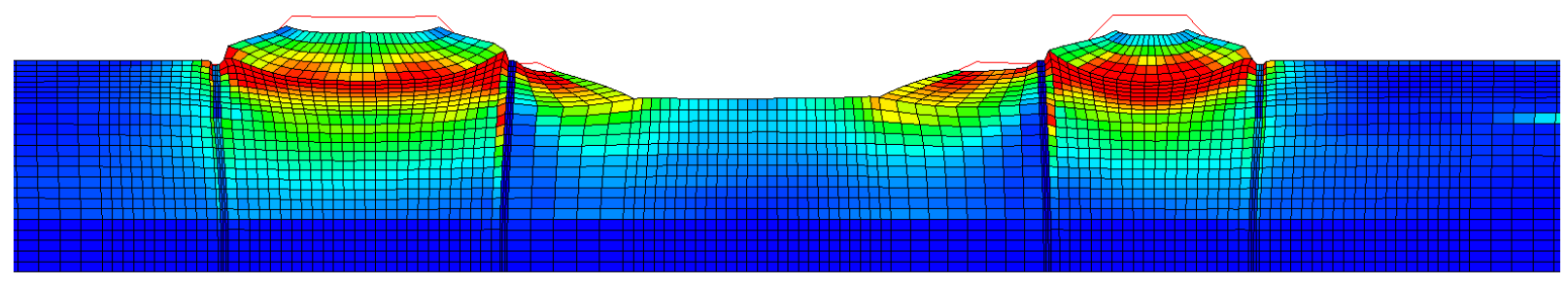

CaseA_6: Both river and land side with long sheet piles

$$
0.0 \%
$$

Over $30.0 \%$ 


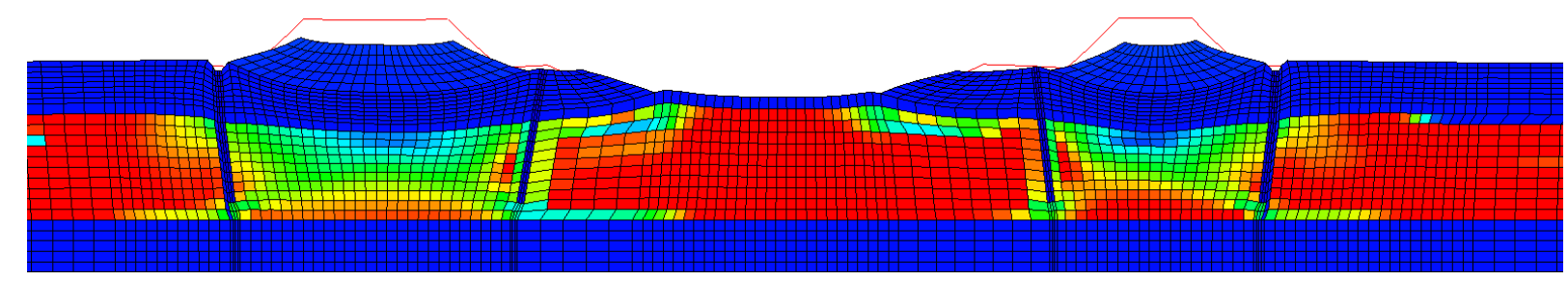

CaseA_3: Both river and land side with short sheet piles

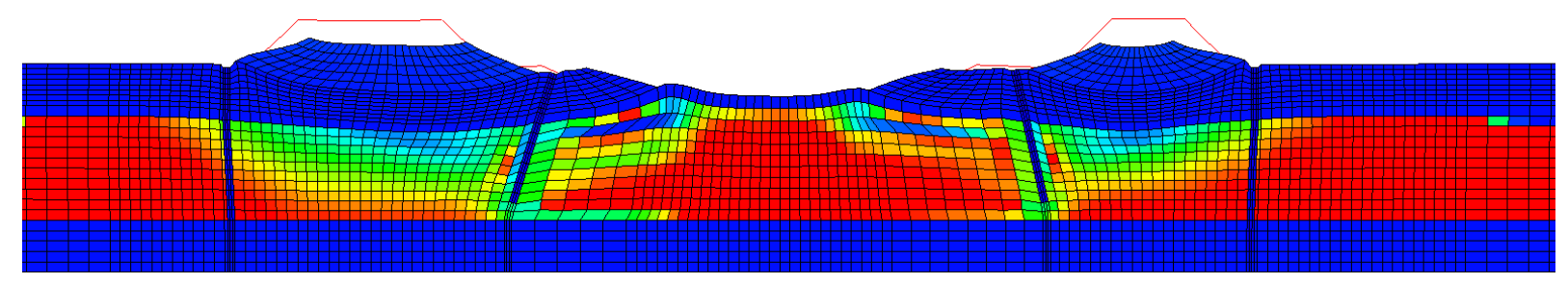

CaseA_4: Short sheet piles at river side and long sheet pile at land side

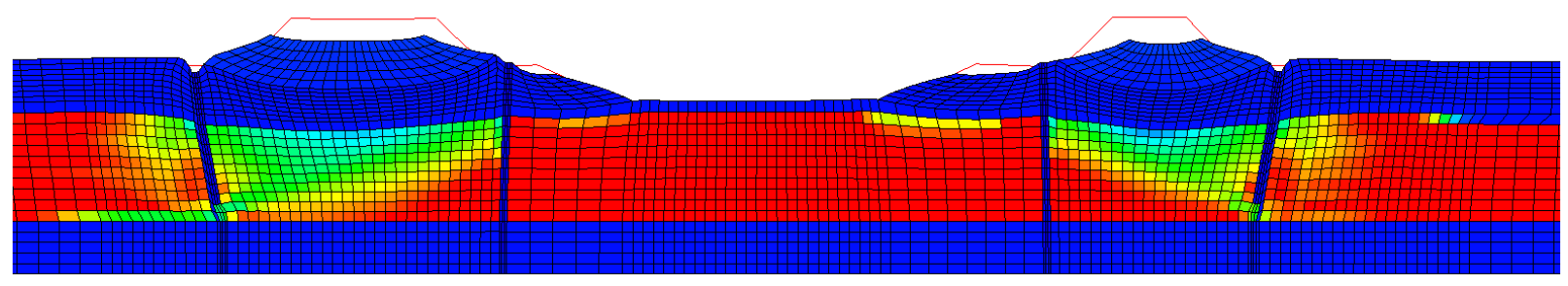

CaseA_5: Long sheet piles at river side and short sheet pile at land side

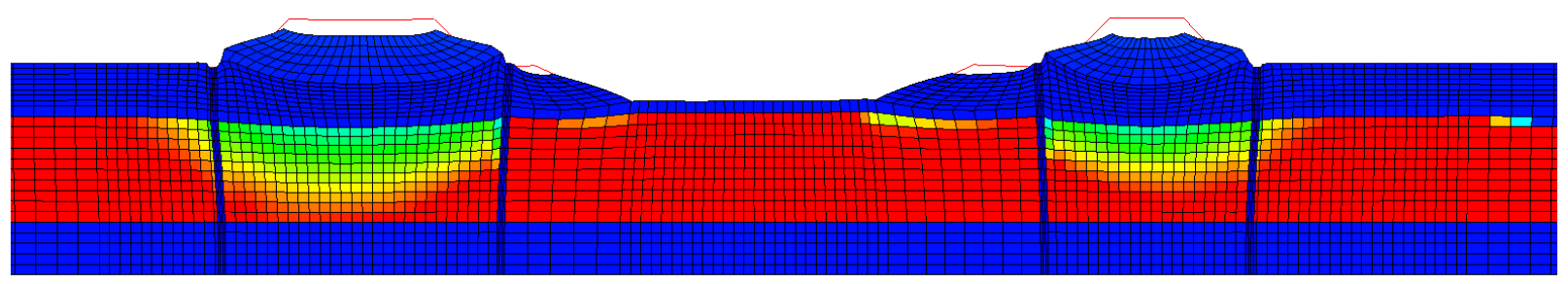

CaseA_6: Both river and land side with long sheet piles
1
(Less structured / remolded)
Over 50
(Highly structured) 


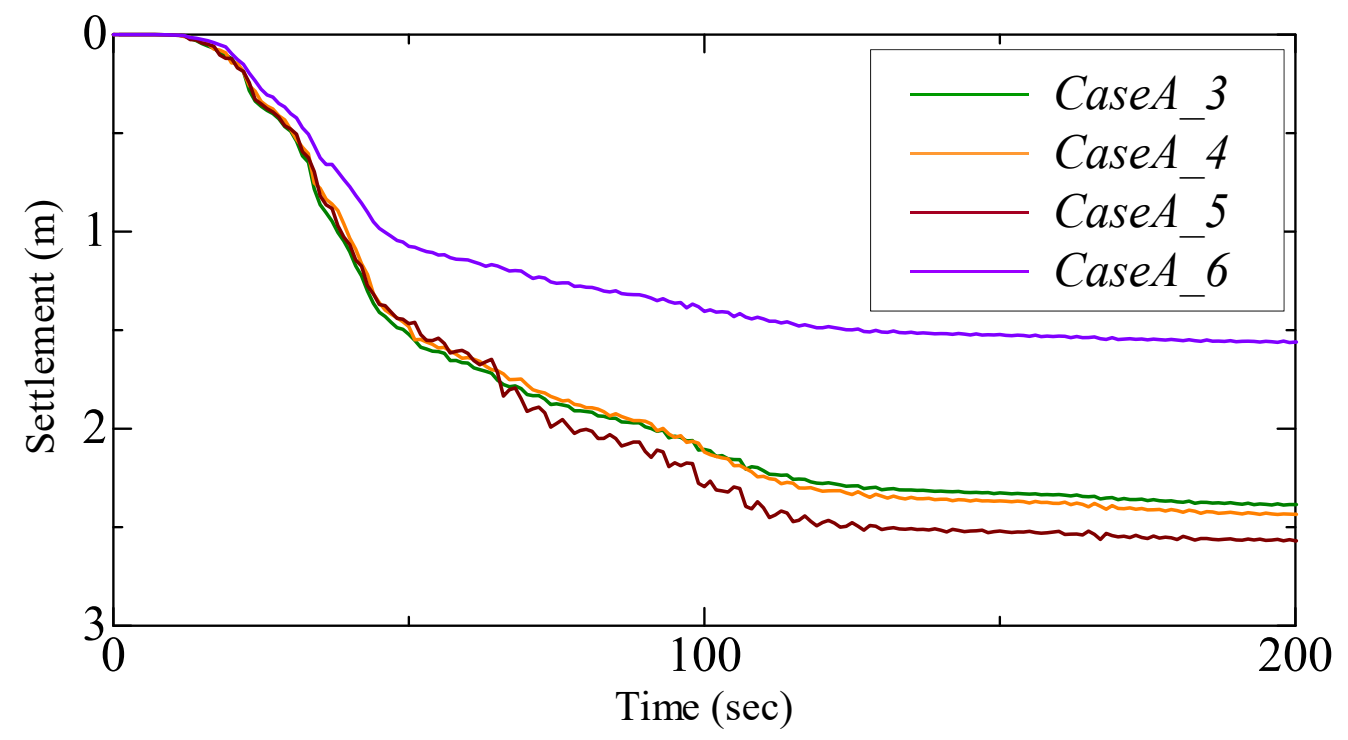




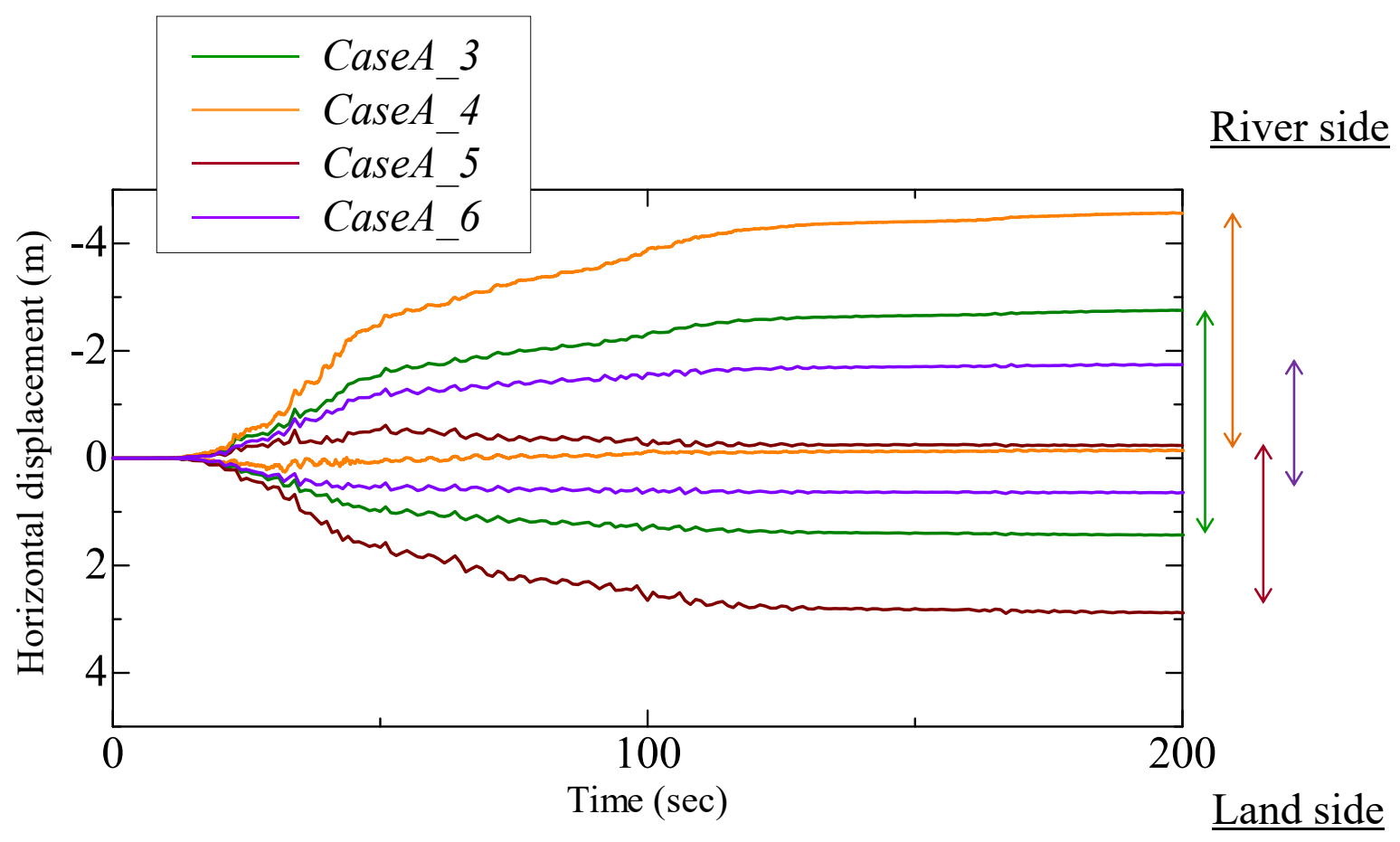


CaseA_3

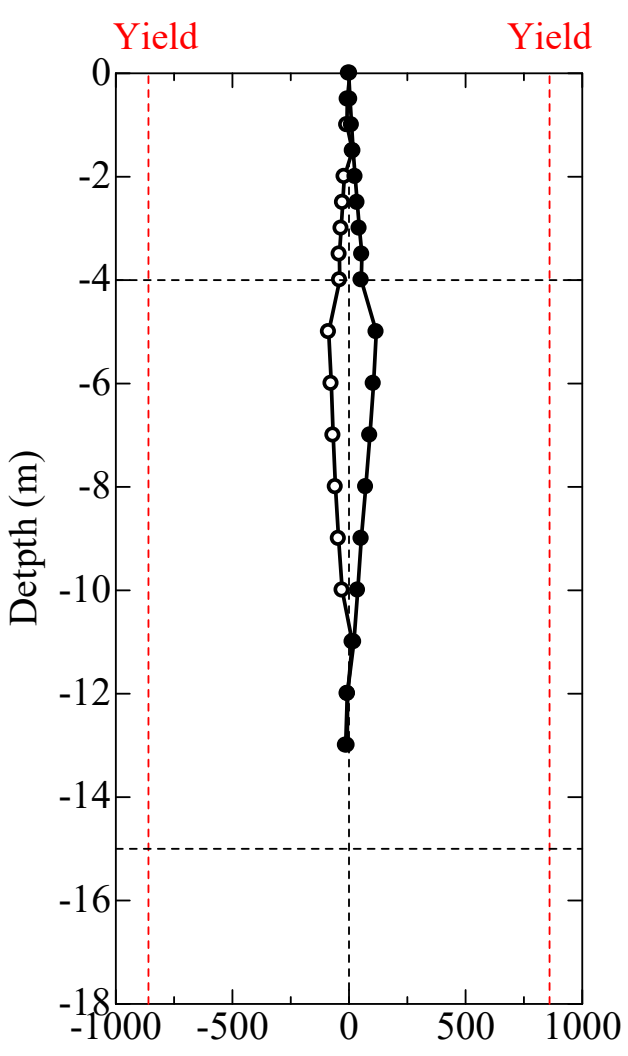

Bending moment $(\mathrm{kN} \cdot \mathrm{m})$
CaseA_4

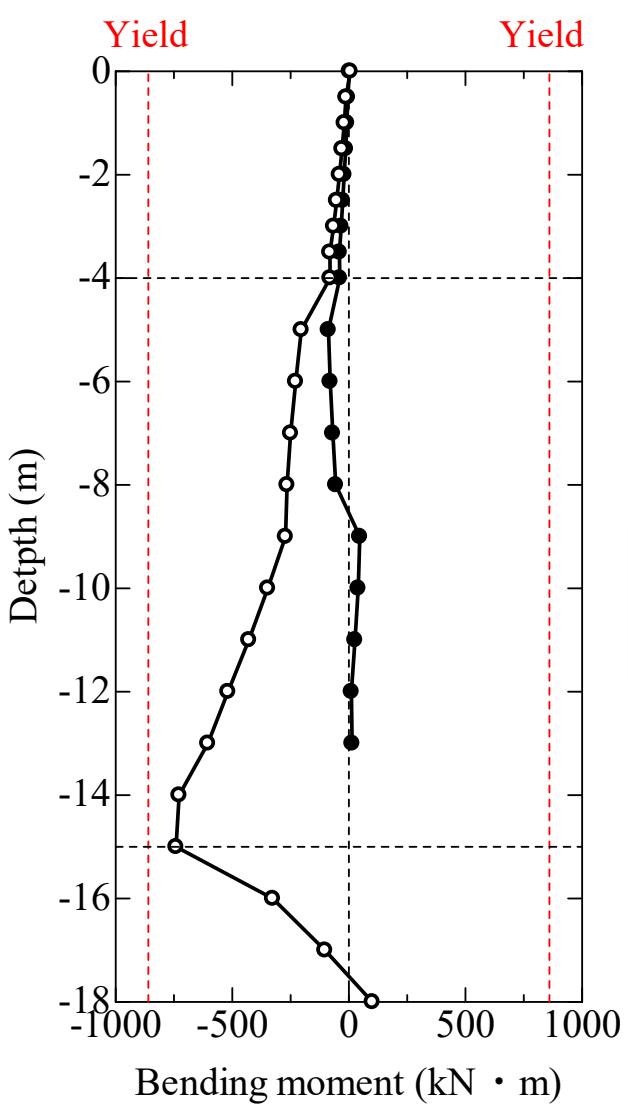

CaseA_6
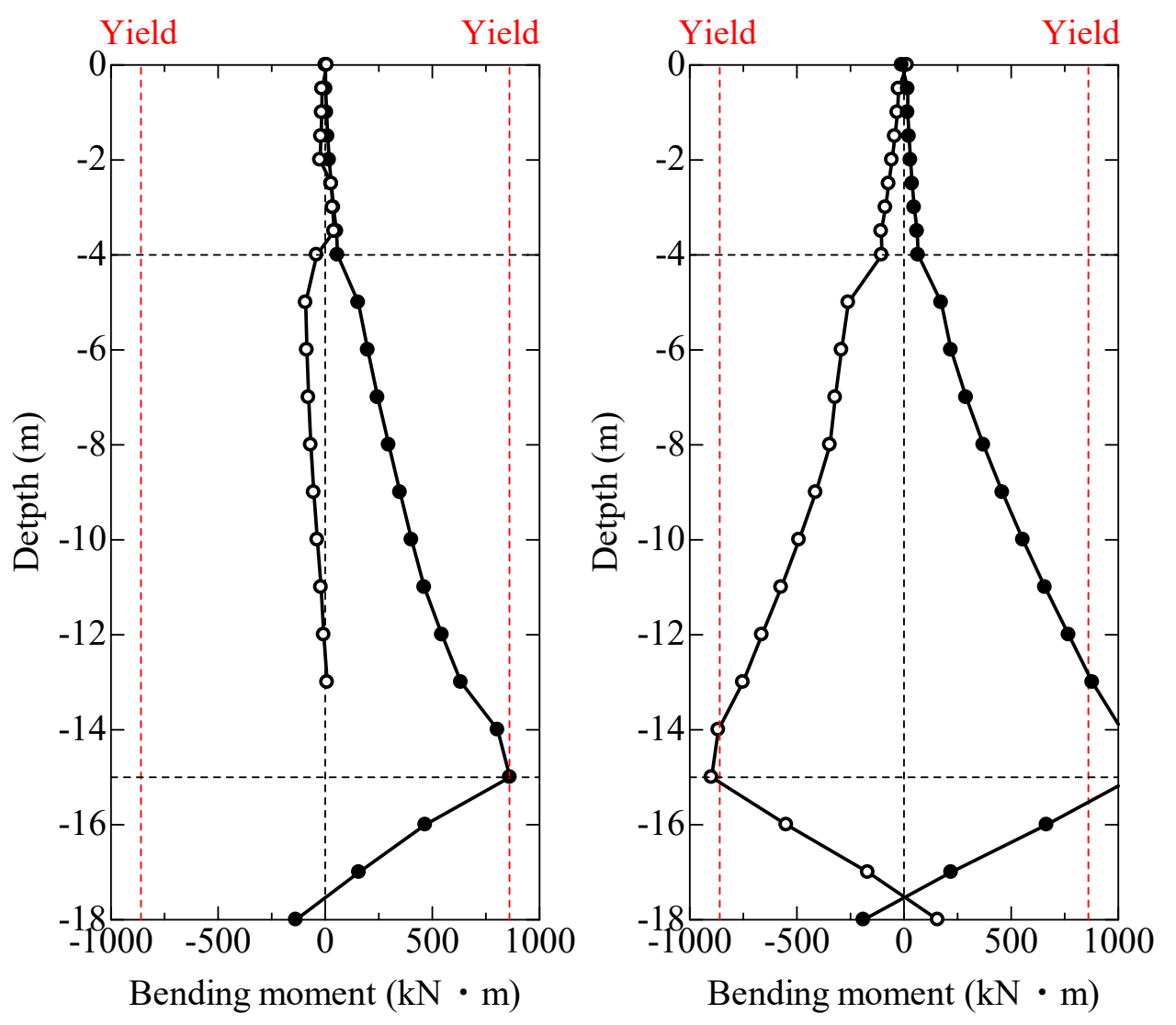

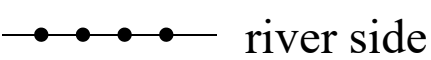

$\multimap \multimap-\infty$ land side 
$\underline{\text { Land side }}$

$\underline{\text { River side }}$

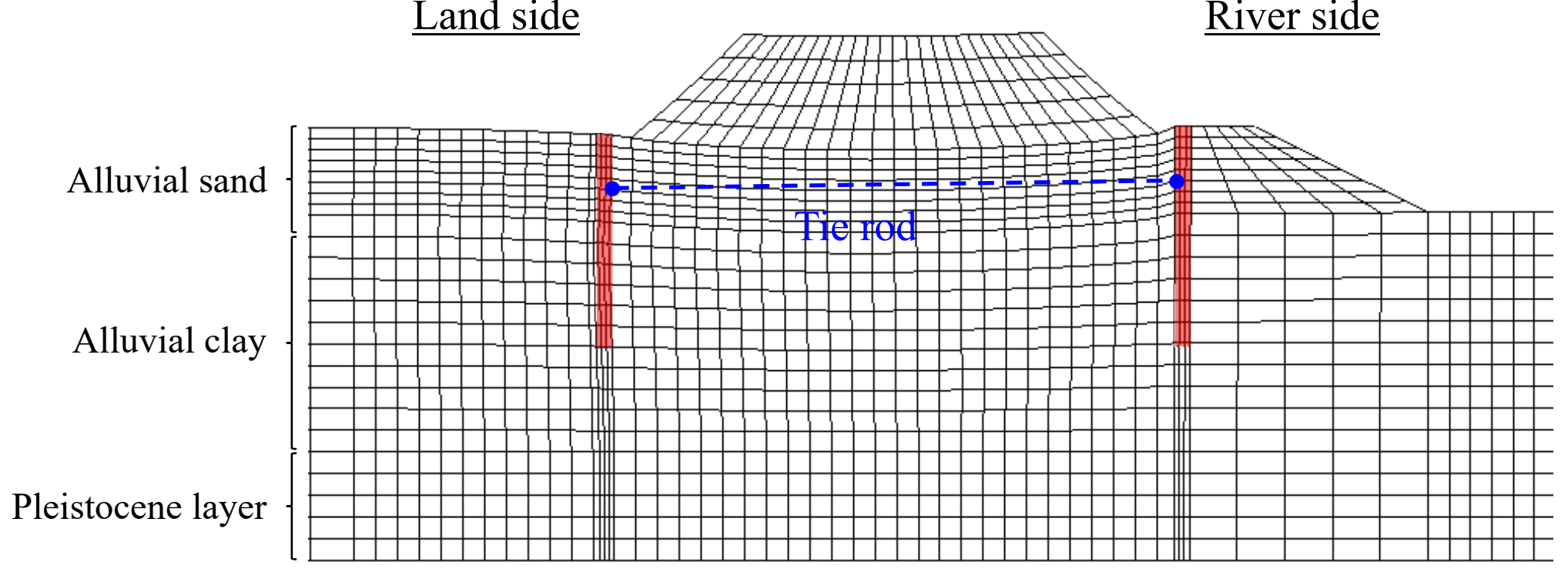




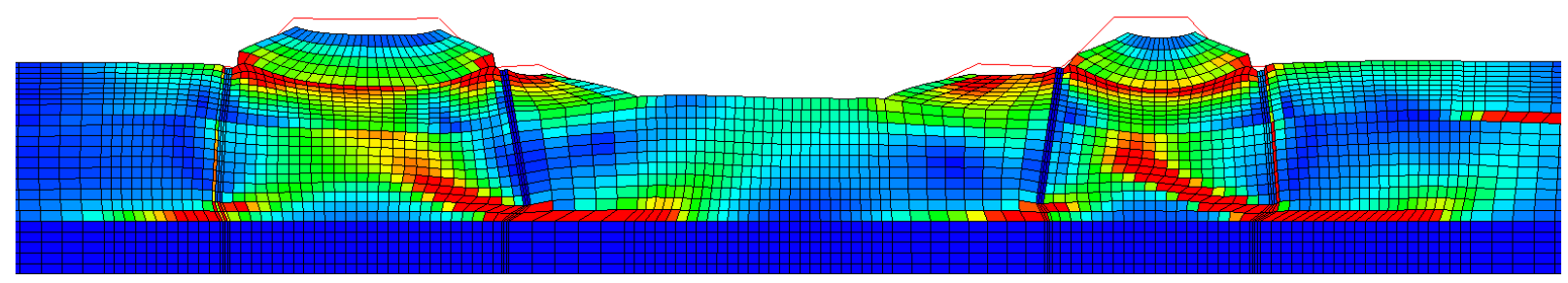

Case A_7: Case A_3 + tie rod $0.0 \%$ Over $30.0 \%$

(a) Shear strain distribution

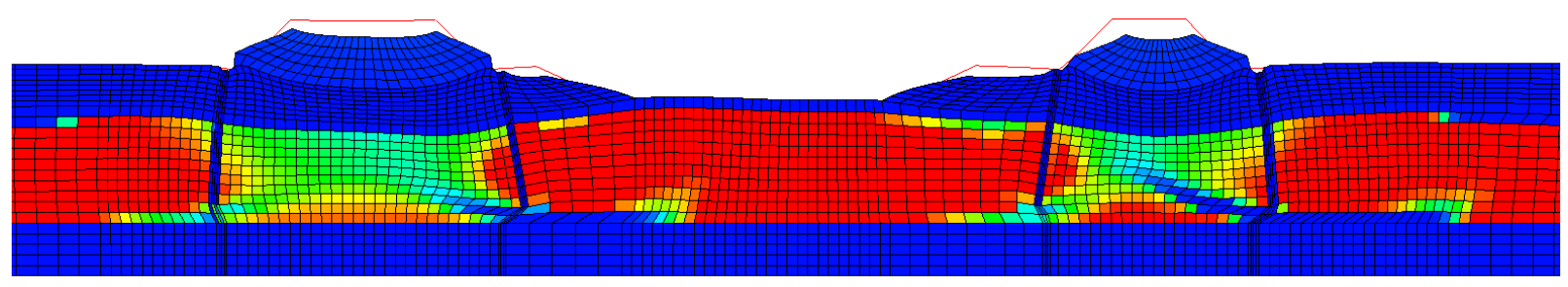

Case A_7: Case A_3 + tie rod

1

(Less structured / remolded)
Over 50

(Highly structured)

(b) Structure distribution 


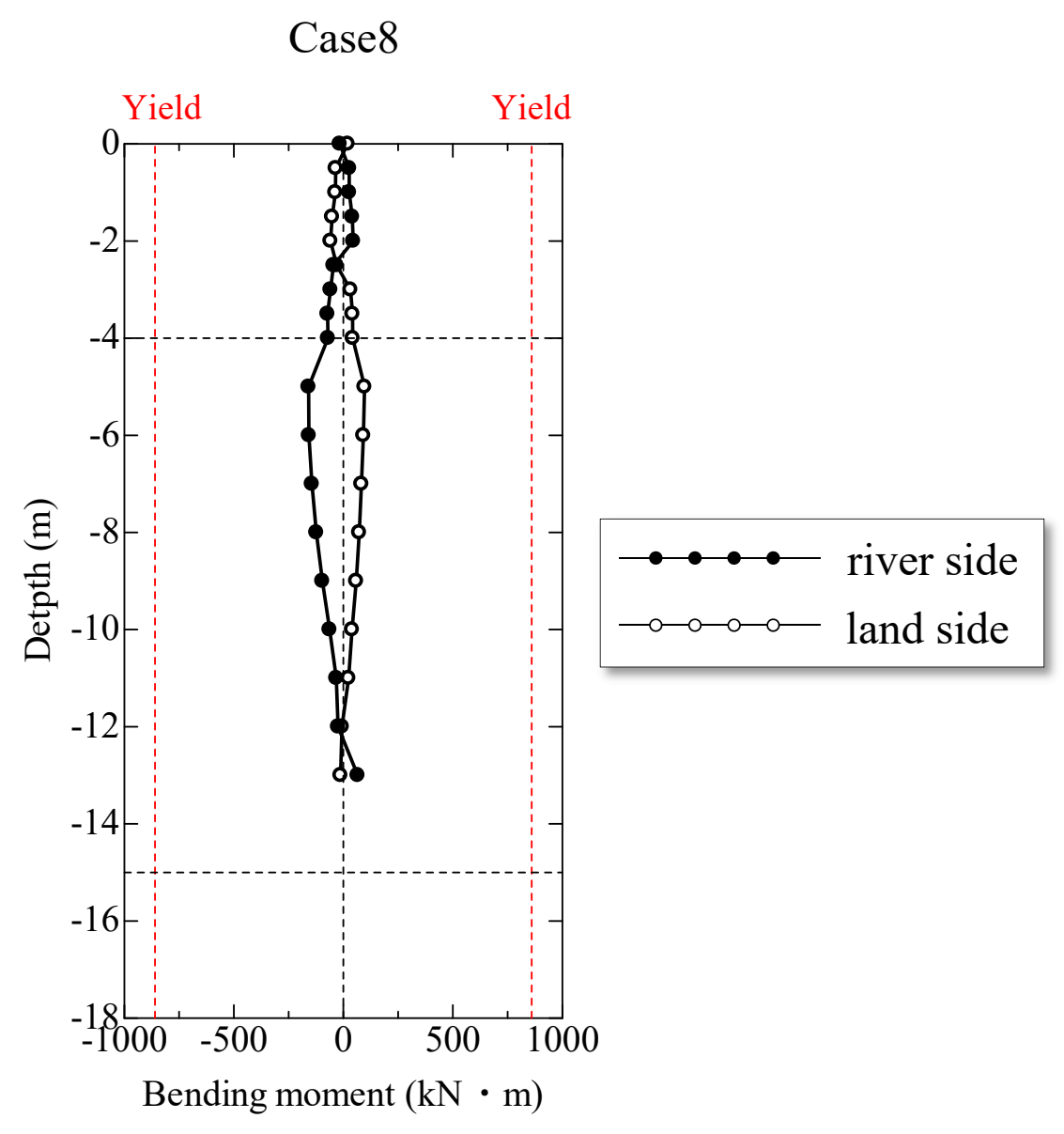



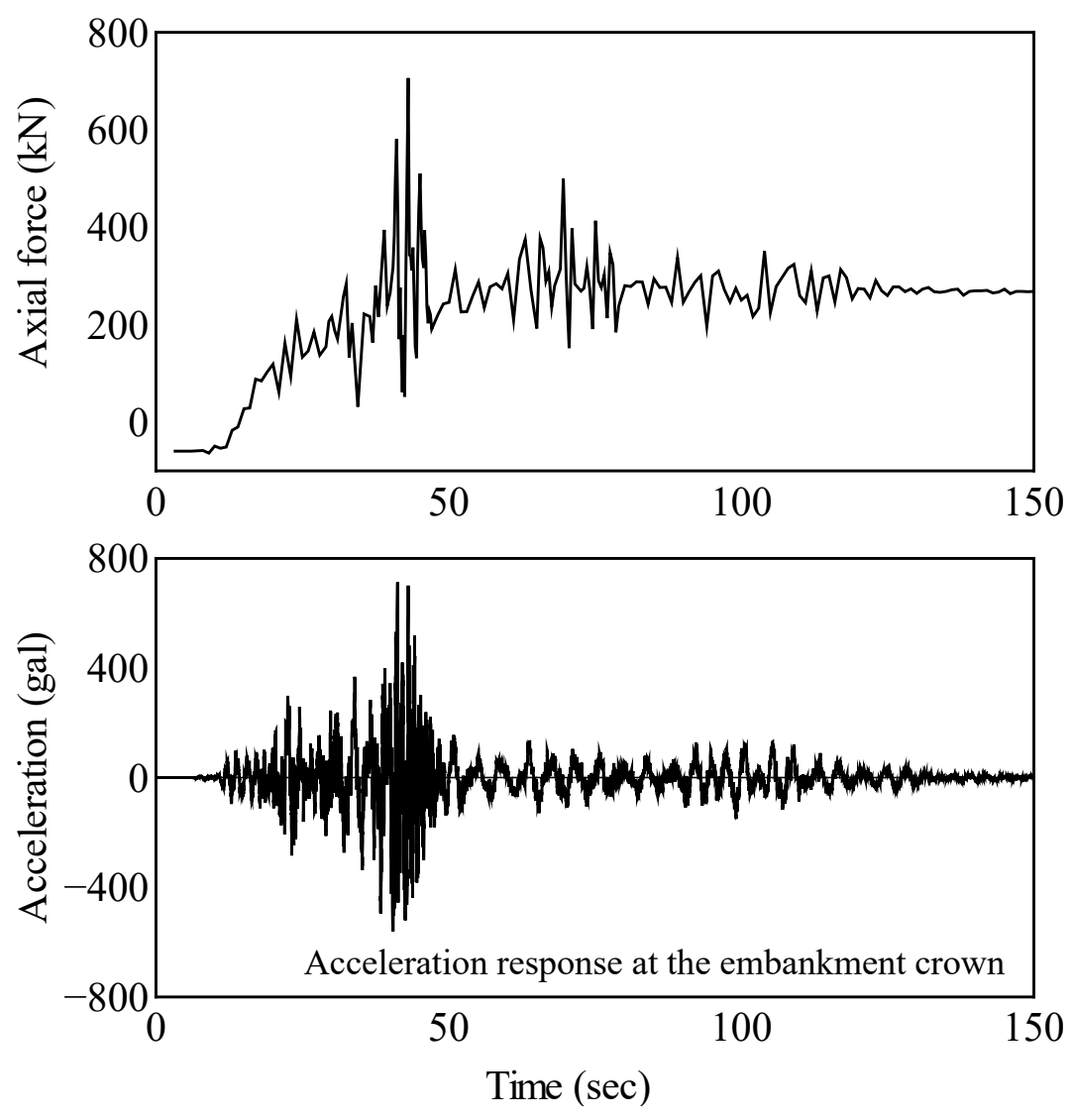
Table 1. Physical properties of each layer.

\begin{tabular}{|c|c|c|c|}
\hline & Embankment & Alluvial sand & Alluvial clay \\
\hline Particle density $\rho_{s}(\mathrm{~g} / \mathrm{cm} 3)$ & 2.51 & 2.67 & 2.71 \\
\hline Liquid limit $w_{L}(\%)$ & 37.3 & NP & 97.4 \\
\hline Plastic limit $w_{p}(\%)$ & 16.3 & NP & 43.3 \\
\hline Plasticity index $I_{p}$ & 21.0 & NP & 54.1 \\
\hline
\end{tabular}


Table 2. Elasto-plastic properties of soils used for the analysis.

\begin{tabular}{lllll}
\hline & Embankment & Alluvial sand & Alluvial clay & Pleistocene layer \\
\hline Elasto-plastic parameters & & & & \\
Critical state index M & 1.38 & 1.33 & 1.50 & 1.50 \\
NCL intercept N & 1.80 & 1.93 & 2.40 & 2.00 \\
Compression index $\tilde{\lambda}$ & 0.225 & 0.083 & 0.210 & 0.080 \\
Swelling index $\widetilde{\kappa}$ & 0.012 & 0.003 & 0.035 & 0.001 \\
Poisson's ratio v & 0.30 & 0.30 & 0.30 & 0.30 \\
Evolution parameters & & & & \\
Degradation index of structure $a$ & 0.80 & 2.20 & 0.45 & 2.00 \\
Ratio of - $D_{v}{ }^{p}$ to $\left\|D_{s}{ }^{p}\right\| c_{s}$ & 0.35 & 0.70 & 0.30 & 0.60 \\
Degradation index of OC $m$ & 2.00 & 0.10 & 10.00 & 10.00 \\
Rotational hardening index $b r$ & 1.20 & 2.00 & 0.01 & 0.00 \\
Limit of rotational hardening $m_{b}$ & 1.00 & 0.70 & 1.00 & 0.00 \\
Initial conditions & & & & \\
Specific volume v & 2.11 & $1.95-1.86$ & $3.09-3.04$ & $1.71-1.69$ \\
Stress ratio $\eta_{0}$ & 0.545 & 0.545 & 0.545 & 0.545 \\
Degree of structure $1 / R^{*}{ }_{0}$ & 4.00 & 1.20 & 95.00 & 1.10 \\
Degree of overconsolidation $1 / R_{0}$ & $1.87-3.06$ & 2.26 & 1.02 & 35.60 \\
Degree of anisotropy $S_{0}$ & 0.000 & 0.375 & 0.000 & 0.000 \\
Soil particle density $\rho_{s}(\mathrm{~g} / \mathrm{cm} 3)$ & 2.51 & 2.67 & 2.71 & 2.65 \\
Mass permeability index $k(\mathrm{~cm} / \mathrm{s})$ & $1.0 \times 10^{-4}$ & $1.0 \times 10^{-3}$ & $1.2 \times 10^{-6}$ & $1.0 \times 10^{-5}$ \\
\hline
\end{tabular}


Table 3. Initial conditions for Cases $A$ and $B$.

\begin{tabular}{lll}
\hline & Case $A$ & Case $B$ \\
& Actual highly structured ground & Simulated disturbed ground \\
\hline Specific volume v & $3.41-3.26$ & $2.59-2.43$ \\
Stress ratio $\eta_{0}$ & 0.545 & 0.545 \\
Degree of structure $1 / R^{*}$ & 95.00 & 1.00 \\
Degree of overconsolidation $1 / R_{0}$ & 1.02 & 1.02 \\
Degree of anisotropy $\varsigma_{0}$ & 0.00 & 0.00 \\
Soil particle density $\rho_{s}(\mathrm{~g} / \mathrm{cm} 3)$ & 2.71 & 2.71 \\
Mass permeability index $k(\mathrm{~cm} / \mathrm{s})$ & $1.2 \times 10^{-6}$ & $1.2 \times 10^{-6}$ \\
\hline
\end{tabular}


Table 4. Conditions of embedded steel pipe sheet piles.

\begin{tabular}{lll}
\hline & \multicolumn{2}{l}{ Existence of sheet pile } \\
\cline { 2 - 3 } & River side & Land side \\
\hline CaseA & None & None \\
CaseA_1 & Short & None \\
CaseA_2 & Long & None \\
CaseA_3 & Short & Short \\
CaseA_4 & Short & Long \\
CaseA_5 & Long & Short \\
CaseA_6 & Long & Long \\
\hline
\end{tabular}


Table 5. Material constants of steel pipe sheet piles.

\begin{tabular}{lll}
\hline & Actual value & $\begin{array}{l}\text { Revised value used } \\
\text { in the analysis }\end{array}$ \\
\hline Density $\rho(\mathrm{g} / \mathrm{cm} 3)$ & 7.85 & 2.05 \\
Poisson's ratio $v$ & 0.3 & 0.3 \\
Young's modulus $E(\mathrm{GPa})$ & 200 & 12.9 \\
Yield stress $\sigma_{y}(\mathrm{MPa})$ & 235 & 15.1 \\
Yield moment $M_{v}(\mathrm{kNm})$ & 860 & 860 \\
\hline
\end{tabular}


Quantified expression of structure, overconsolidation, anisotropy, and their respective evolution rules

4 Naturally deposited soils, whether clayey or sandy, generally exist in a structured and overconsolidated state. To

5 describe the deformation behavior of a soil in this state, we have to start from the base of an elasto-plastic model of

6 a unstructured soil in a state of normal consolidation. Given that a soil in this unstructured and normally

7 consolidated state still possesses anisotropy, the method presented in this paper is based on the corrected Cam-clay

8 model of Roscoe and Burland (1968), with the introduction of the rotational hardening concept of Sekiguchi and

9 Ohta (1977), which treats the stress parameter $\eta^{*}$ and its evolution rule as an expression of anisotropy. The

10 degrees of structure and overconsolidation are then introduced and quantified by means of two concepts: the

11 superloading surface for structure (Asaoka et al. 1998, Asaoka et al. 2000, Asaoka et al. 2002), and the subloading surface for overconsolidation (Hashiguchi 1978, Hashiguchi 1989, Asaoka et al. 1997). That is to say, the degree of structure is expressed by means of a superloading surface situated on the outside of the Cam-clay normal-yield

14 surface and similar to it, with the center of similarity being the origin $p^{\prime}=q=0$ and the similarity rate being

15 given by $R^{*}$, where $\left(0<R^{*} \leq 1\right)$. At the same time, the overconsolidation state is expressed by means of a subloading surface situated on the inside of the superloading surface and again similar to it, with the center of similarity $p^{\prime}=q=0$; the similarity rate $R$, where $(0<R \leq 1)$; and the reciprocal $1 / R$ is the overconsolidation

tensor $\boldsymbol{T}^{\prime}$ (tension: positive): $p^{\prime}=-\operatorname{tr} \boldsymbol{T}^{\prime} / 3, q=\sqrt{3 / 2 \boldsymbol{S} \cdot \boldsymbol{S}}$. 
induces a loss of structure, $R^{*}$ will approach 1, which is the evolution rule for $R^{*}$. Similarly, the closer $R$ is

to 0 , the more overconsolidated the state of the soil; however, as $R$ increases toward 1 with plastic deformation,

of structure induced by progressive plastic deformation can be assumed to induce a simultaneous release from

in the Cam-clay model. The relative positions of the three loading surfaces, assuming conditions of axial symmetry,

application of various elasto-plastic principles such as the associated flow rule and Prager's consistency condition.

$$
\begin{aligned}
& \mathrm{MD} \ln \frac{\tilde{p}^{\prime}}{\tilde{p}_{0}^{\prime}}+\mathrm{MD} \ln \frac{\mathrm{M}^{2}+\eta^{* 2}}{\mathrm{M}^{2}}+\int_{0}^{t} J \operatorname{tr} D^{p} d \tau=f\left(\tilde{p}^{\prime}, \eta^{*}\right)+\int_{0}^{t} J \operatorname{tr} \boldsymbol{D}^{p} d \tau=0 \\
& f\left(p^{\prime}, \eta^{*}\right)+\mathrm{MD} \ln R^{*}-\mathrm{MD} \ln R+\int_{0}^{t} J \operatorname{tr} D^{p} d \tau=0
\end{aligned}
$$

Here, $\mathrm{D}=(\tilde{\lambda}-\tilde{\kappa}) / \mathrm{M} /\left(1+\mathrm{e}_{0}\right)$ is the dilatancy coefficient; $\mathrm{M}, \tilde{\lambda}, \tilde{\kappa}$, and $\mathrm{e}_{0}$ are the critical state constant, compression index, swelling index, and initial void ratio, respectively; $J=(1+\mathrm{e}) /\left(1+\mathrm{e}_{0}\right)$, where e is the void ratio at time $t=t$; and $-\int_{0}^{t} J \operatorname{tr} \boldsymbol{D}^{p} d \tau$ (compression: positive) corresponds to the plastic volumetric strain $\eta^{*}$. The expression of anisotropy is obtained using the rotational hardening variable $\boldsymbol{\beta}$, where $\boldsymbol{\beta}=\boldsymbol{0}$ expresses a state of no anisotropy, from the calculation $\eta^{*}=\sqrt{3 / 2 \hat{\boldsymbol{\eta}} \cdot \hat{\boldsymbol{\eta}}} ; \hat{\boldsymbol{\eta}}=\boldsymbol{\eta}-\boldsymbol{\beta} ; \boldsymbol{\eta}=\boldsymbol{S} / p^{\prime} ;$ and $\boldsymbol{S}=\boldsymbol{T}^{\prime}+p^{\prime} \boldsymbol{I}$. In the present paper, the evolution rules for $R^{*}, \quad R$, and $\boldsymbol{\beta}$ are given by the following equations. 
Evolution rule for $R^{*}: \dot{R}^{*}=J \sqrt{\frac{2}{3}}\left\|\boldsymbol{D}_{s}^{p}\right\|, \quad U^{*}=\frac{a}{\mathrm{D}} R^{* b}\left(1-R^{*}\right)^{c}$

$$
\text { Evolution rule for } \boldsymbol{\beta} \quad: \quad \stackrel{\boldsymbol{\beta}}{=}=J \frac{b r}{\mathrm{D}} \sqrt{\frac{2}{3}}\left\|\boldsymbol{D}_{s}^{p}\right\|\|\hat{\boldsymbol{\eta}}\|\left(m_{b} \frac{\hat{\boldsymbol{\eta}}}{\|\hat{\boldsymbol{\eta}}\|}-\boldsymbol{\beta}\right)
$$

Here $\boldsymbol{D}^{p}$ is the plastic stretching tensor, $\boldsymbol{D}_{s}^{p}$ is the deviator component of $\boldsymbol{D}^{p}$, and \|\| represents $\boldsymbol{D}^{p}$

43 norms. In eq. (A5), $\boldsymbol{\beta}$ is the Green and Nagdhi's rate of $\boldsymbol{\beta}$. The parameter groups for the evolution rules in eqs. (A3) - (A8) all consists of constants, and from their respective functions, we may call $a, b, c$ the degradation indices of structure; $m$ the degradation index of overconsolidation; $b r$ the rotational hardening index; and $m_{b}$ the rotational hardening limit constant.

50 Here $\boldsymbol{E}$ is the elastic modulus tensor, $\stackrel{\circ}{\boldsymbol{T}}^{\prime}$ is the Green and Naghdi's rate of $\boldsymbol{T}^{\prime}$, and $\Lambda$ is the expression of 51 the plastic multiplier $\lambda$ in terms of stretching $\boldsymbol{D}$. Further, we can establish the relations

$$
\begin{aligned}
\mathrm{M}_{s}{ }^{2} & =\mathrm{M}_{a}{ }^{2}+b r \frac{4 \mathrm{M} \eta^{* 2}}{\mathrm{M}^{2}+\eta^{* 2}}\left(m_{b} \eta^{*}-\sqrt{\frac{3}{2}} \hat{\boldsymbol{\eta}} \cdot \boldsymbol{\beta}\right) \\
& -\mathrm{MD}\left(\frac{U^{*}}{R^{*}} 2 \eta^{*}+\frac{U}{R} \sqrt{6 \eta^{* 2}+\frac{1}{3}\left(\mathrm{M}_{a}{ }^{2}-\eta^{2}\right)^{2}}\right)
\end{aligned}
$$

and

$$
\mathrm{M}_{a}^{2}=\mathrm{M}^{2}+\zeta^{2}, \quad \zeta=\sqrt{3 / 2}\|\boldsymbol{\beta}\|
$$


55 The slope $\mathrm{M}_{s}$ of the threshold between hardening and softening $q=\mathrm{M}_{s} p^{\prime}$, obtained under loading conditions $56 \lambda>0$, varies according to structural degradation, loss of overconsolidation, and development or loss of anisotropy,

57 as well as with the current stress ratio. Similarly, the slope $\mathrm{M}_{a}$ of the threshold between plastic compression and

expansion $q=\mathrm{M}_{a} p^{\prime}$ varies in response to the development or loss of anisotropy. For details, the reader is referred

59 to Asaoka et al. (2002).

60 
Figure captions for Appendix

$62 \quad$ Figure A1

Three loading surfaces

63 
64

65

66

67

68

69

70

71

72

73

74

75

76

\section{References for Appendix}

Asaoka, A., Noda, T., and Fernando, G.S.K. 1997. Effects of changes in geometry on the linear elastic consolidation deformation. Soils and Foundations, 37(1): 29-39.

Asaoka, A., Nakano, M., and Noda, T. 1998. Superloading yield surface concept for the saturated structured soils. In Proceedings of Fourth European Conference on Numerical Methods in Geotechnical Engineering, Udine, Italy, 14-16 October 1998. International Centre for Mechanical Sciences, Udine, Italy, pp. 233-242.

Asaoka, A., Nakano, M., and Noda, T. 2000. Superloading yield surface concept for highly structured soil behavior. Soils and Foundations, 40(2): 99-110.

Asaoka, A., Noda, T., Yamada, E., Kaneda, K., and Nakano, M. 2002. An elasto-plastic description of two distinct volume change mechanisms of soils. Soils and Foundations, 42(5): 47-57.

Hashiguchi, K. 1978. Plastic constitutive equations of granular materials. In Proceedings of the US-Japan Seminar on Continuum Mechanical and Statistical Approaches in the Mechanics of Granular Materials, Sendai, Japan, 5-9 June 1978. Eds. Cowin, S.C., National Science Foundation, and Satake, M., Japan Society for the Promotion of Science, Tokyo, Japan, pp. 321-329.

Hashiguchi, K. 1989. Subloading surface model in unconventional plasticity. International Journal of Solids and Structures, 25: 917-945.

Roscoe, K.H., and Burland, J.B. On the generalized stress-strain behaviour of 'wet' clay. In Engineering Plasticity. Edited by J. Heyman and F.A. Leckie. Cambridge University Press, Cambridge, England, pp. 535-609.

Sekiguchi, H., and Ohta, H. 1977. Induced anisotropy and time dependency in clays. In Proceedings of the Ninth 


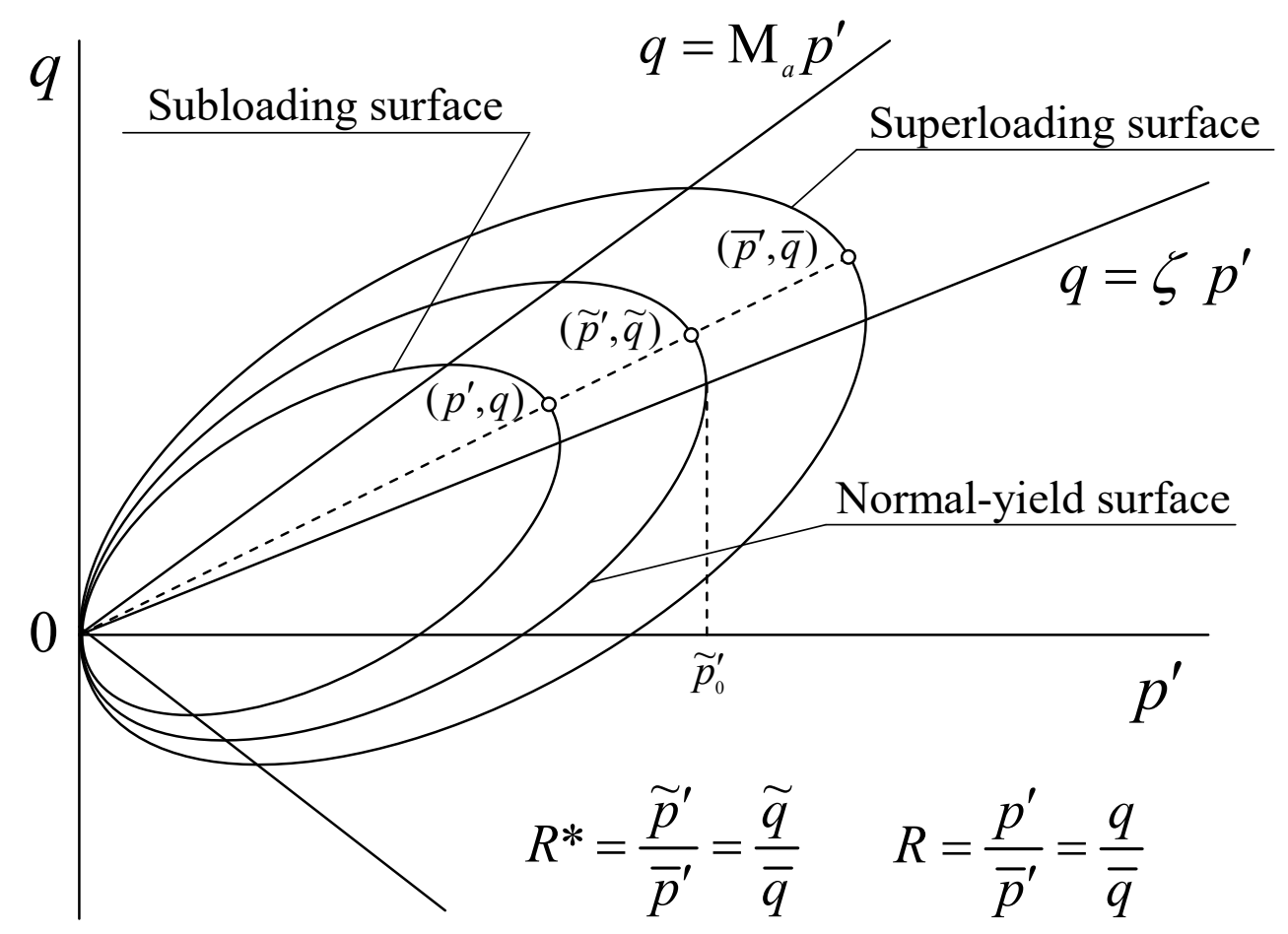

